ARTICLE

\title{
IL-17-producing $\gamma \delta$ T cells switch migratory patterns between resting and activated states
}

Duncan R. McKenzie ${ }^{1}$, Ervin E. Kara ${ }^{1} \dagger$, Cameron R. Bastow ${ }^{1}$, Timona S. Tyllis ${ }^{1}$, Kevin A. Fenix ${ }^{1}$, Carly E. Gregor ${ }^{1}$, Jasmine J. Wilson ${ }^{1}$, Rachelle Babb ${ }^{1, \dagger}$, James C. Paton ${ }^{1,2}$, Axel Kallies ${ }^{3,4}$, Stephen L. Nutt ${ }^{3,4}$, Anne Brüstle ${ }^{5}$, Matthias Mack ${ }^{6}$, lain Comerford ${ }^{1, \star} \&$ Shaun R. McColl ${ }^{1,7, \star}$

Interleukin 17-producing $\gamma \delta \mathrm{T}(\gamma \delta \mathrm{T} 17)$ cells have unconventional trafficking characteristics, residing in mucocutaneous tissues but also homing into inflamed tissues via circulation. Despite being fundamental to $\gamma \delta \mathrm{T} 17$-driven early protective immunity and exacerbation of autoimmunity and cancer, migratory cues controlling $\gamma \delta T 17$ cell positioning in barrier tissues and recruitment to inflammatory sites are still unclear. Here we show that $\gamma \delta \mathrm{T} 17$ cells constitutively express chemokine receptors CCR6 and CCR2. While CCR6 recruits resting $\gamma \delta \mathrm{T} 17$ cells to the dermis, CCR2 drives rapid $\gamma \delta \mathrm{T} 17$ cell recruitment to inflamed tissues during autoimmunity, cancer and infection. Downregulation of CCR6 by IRF4 and BATF upon $\gamma \delta \mathrm{T} 17$ activation is required for optimal recruitment of $\gamma \delta T 17$ cells to inflamed tissue by preventing their sequestration into uninflamed dermis. These findings establish a lymphocyte trafficking model whereby a hierarchy of homing signals is prioritized by dynamic receptor expression to drive both tissue surveillance and rapid recruitment of $\gamma \delta T 17$ cells to inflammatory lesions.

\footnotetext{
${ }^{1}$ Department of Molecular \& Cellular Biology, University of Adelaide, Adelaide, South Australia 5005, Australia. ${ }^{2}$ Research Centre for Infectious Diseases, University of Adelaide, Adelaide, South Australia 5005, Australia. ${ }^{3}$ The Walter and Eliza Hall Institute of Medical Research, Parkville, Victoria 3052, Australia. ${ }^{4}$ Department of Medical Biology, University of Melbourne, Parkville, Victoria 3010, Australia. ${ }^{5}$ Department of Immunology and Infectious Diseases, John Curtin School of Medical Research, Australian National University, Canberra, Australian Capital Territory 2601, Australia. ${ }^{6}$ Department of Internal Medicine II, University Hospital Regensburg, Regensburg 93042, Germany. ${ }^{7}$ Centre for Molecular Pathology, University of Adelaide, Adelaide, South Australia 5005, Australia. * These authors contributed equally to this work. †Present address(es): Laboratory of Molecular Immunology, The Rockefeller University, New York, New York 10065, USA. (E.E.K.); Department of Medicine, Albert Einstein College of Medicine, New York, New York 10561, USA. (R.B.). Correspondence and requests for materials should be addressed to I.C. (email: iain.comerford@adelaide.edu.au) or to S.R.M. (email: shaun.mccoll@adelaide.edu.au).
} 
nterleukin-17-producing $\gamma \delta \mathrm{T}$ cells $(\gamma \delta \mathrm{T} 17$ cells $)$ are innate-like lymphocytes crucial for early defence against extracellular bacterial and fungal pathogens. $\gamma \delta \mathrm{T} 17$ effector function is programmed in $\mathrm{V} \gamma 4^{+}$and $\mathrm{V} \gamma 6^{+}$cells during thymic development, resulting in their homeostatic localization to barrier tissues and ability to be rapidly activated by innate-derived cytokines $^{1,2}$. Production of interleukin 17A (IL-17A) and other inflammatory cytokines by $\gamma \delta \mathrm{T} 17$ cells within hours of pathogen encounter orchestrates early neutrophil responses critical for mucocutaneous defence ${ }^{3-5}$. However, dysregulated $\gamma \delta \mathrm{T} 17$ cell responses contribute to pathogenesis associated with several models of autoimmunity and can enhance tumour growth and metastasis $^{1,6-9}$.

How $\gamma \delta \mathrm{T} 17$ cells populate homeostatic barrier tissues and then infiltrate inflamed tissues from circulation is unclear. $\gamma \delta \mathrm{T} 17$ cells seed dermis and mucosal tissues during perinatal life ${ }^{10}$. Although parabiosis experiments demonstrate that the majority of $\mathrm{V} \gamma 4^{+}$ $\gamma \delta \mathrm{T} 17$ cells in skin-draining lymph nodes (sLNs) are permanently resident ${ }^{11}$, studies using photolabelling, adoptive transfers and receptor antagonism suggest that $\gamma \delta \mathrm{T} 17$ cells constitutively circulate between dermis, sLNs and blood ${ }^{10,12-14}$. Nevertheless, sLN $\gamma \delta$ T17 cells expand during autoimmune inflammation and infiltrate target tissues via circulation ${ }^{1,9}$. Furthermore, dermal $\mathrm{V} \gamma 4^{+} \gamma \delta \mathrm{T} 17$ cells home from skin to sLNs, proliferate, and repopulate inflamed and distal unaffected skin during psoriasis ${ }^{15}$. Thus despite a largely tissue-restricted distribution, $\gamma \delta \mathrm{T} 17$ cells are motile and move between lymphoid and barrier tissues under homeostasis and experimental inflammatory conditions.

Chemokine receptor CCR6, involved in both homeostatic and inflammatory trafficking of leukocytes in barrier tissues, is expressed by both $\mathrm{T}$ helper 17 (Th17) and $\gamma \delta \mathrm{T} 17$ cells $^{16,17}$. We reported a largely redundant function for CCR6 in recruitment of granulocyte-macrophage colony stimulating factor-producing encephalitogenic Th17 cells to the central nervous system (CNS) during experimental autoimmune encephalomyelitis (EAE). Instead, these cells display a CCR6 ${ }^{-} \mathrm{CCR} 2^{+}$phenotype and infiltrate the CNS via CCR2, which is critical for T-celldriven pathology ${ }^{18}$. In $\gamma \delta \mathrm{T} 17$ cell biology, CCR6 has a debated function in regulating $\mathrm{V} \gamma 4^{+}$cell homeostasis, and is reported to direct $\gamma \delta \mathrm{T} 17$ cell trafficking during inflammation ${ }^{10,11,19}$. However, $\mathrm{V} \gamma 4^{+}$cells homing from inflamed skin to sLNs during psoriasis predominantly lack CCR6 expression ${ }^{14}$. By contrast, CCR2 is implicated in the migration of $\gamma \delta \mathrm{T} 17$ cells to psoriatic skin and arthritic synovium ${ }^{15,20}$, pointing to a clear interplay between CCR6 and CCR2 function in control of $\gamma \delta \mathrm{T} 17$ cell homing. Nevertheless, a clear understanding of $\gamma \delta \mathrm{T} 17$ cell trafficking mechanisms at rest and during inflammation is lacking.

Here, we find that CCR6 controls homeostatic $\gamma \delta \mathrm{T} 17$ cell trafficking to the dermis, whereas constitutive CCR2 expression drives their rapid homing to inflammatory sites. In models of autoimmunity, cancer and infection, activation-induced downregulation of CCR6 releases $\gamma \delta \mathrm{T} 17$ cells from their homeostatic immunosurveillance trafficking circuit through the skin and circulation, which then enhances their CCR2-dependent homing to inflamed tissue. Therefore, the dynamic interplay between CCR6 and CCR2 expression defines $\gamma \delta$ T17 cell trafficking patterns between resting and activated states.

\section{Results}

$\gamma \delta \mathrm{T} 17$ cells downregulate CCR6 upon activation. We recently reported that Th17 cell development during EAE is coupled with a dynamic, temporally regulated switch from CCR6 to CCR2 expression as Th17 cells propagate their differentiation. Expression patterns of CCR6 and CCR2 define distinct effector phenotypes of Th17 cells, with a CCR6 ${ }^{-} \mathrm{CCR} 2^{+}$phenotype marking the encephalitogenic granulocyte-macrophage colony-stimulating factor/interferon- $\gamma$-producing population ${ }^{18}$. Unlike Th17 cells, $\gamma \delta T 17$ cell effector function is programmed during thymic development and these cells populate barrier tissues prior to inflammation $2,21,22$. Thus, we initially examined CCR6 and CCR2 expression in sLN and dermis in unimmunized $I l 17 a^{C r e} \times$ Rosa $6^{\text {PYP }}$ mice, where $I l 17 a$ expression drives permanent marking of cells with $\mathrm{eYFP}^{23}$. $\gamma \delta \mathrm{T} 17$ cells in these compartments constitutively co-expressed CCR2 and CCR6 (Fig. 1a and Supplementary Fig. 1a). Expression of CCR6 and CCR2 was restricted to $\gamma \delta \mathrm{T}$ cells bearing a CD27-CD44 ${ }^{\text {hi }}$ phenotype, characteristic of $\gamma \delta \mathrm{T} 17$ cells (Supplementary Fig. 2a) ${ }^{24}$. CCR6/CCR2 co-expression was similar between $\mathrm{V} \gamma 4^{+}$and $\mathrm{V} \gamma 6^{+} \gamma \delta \mathrm{T} 17$ cell subsets as distinguished by both $\mathrm{V} \gamma 4$ expression and CD3/T-cell receptor (TCR) expression level, as previously reported ('CD3 ${ }^{\text {bright }}$ staining') ${ }^{25}$ (Supplementary Fig. 1b,c), and both receptors were functional as determined by ex vivo chemotaxis (Fig. 1b). However, examination of $\gamma \delta \mathrm{T} 17$ cells from diverse tissues revealed a heterogeneous pattern of CCR6 expression. While thymic and most lymphoid $\gamma \delta \mathrm{T} 17$ cells uniformly expressed both CCR6 and CCR2, populations of $\gamma \delta \mathrm{T} 17$ cells lacking CCR6 expression $\left(\mathrm{CCR} 6^{-} \mathrm{CCR} 2^{+}\right.$) were prominent in lung and gut-associated tissues (Fig. 1c). As the gut is tonically immunologically active due to interactions with commensal microbiota, we hypothesized that $\gamma \delta \mathrm{T} 17$ cells downregulate CCR6 expression during inflammation.

In support of this idea, activation of sLN and spleen $\gamma \delta \mathrm{T} 17$ cells in vivo during EAE resulted in downregulation of CCR6 expression compared to unimmunized mice (Fig. 1d). CNS-infiltrating $\gamma \delta \mathrm{T} 17$ cells were also largely $\mathrm{CCR}^{-}{ }^{-}$. BrdU incorporation revealed that CCR6 expression was downregulated in proliferated $\gamma \delta \mathrm{T} 17$ cells, while $\mathrm{BrdU}^{-}$cells remained CCR6 ${ }^{+}$ (Fig. 1e). Other $\gamma \delta$ T-cell subsets did not express CCR2 or CCR6 at rest, and did not gain expression of these receptors over the course of EAE (Supplementary Fig. 2a). Unlike Th17 cells, $\gamma \delta \mathrm{T} 17$ cells are predominantly activated by TCR-independent signals including IL-23 and IL- $1 \beta^{1}$. In vitro stimulation of lymphocytes with a range of known stimuli including IL-23/IL-1 $\beta$, IL-23/IL-18 (ref. 26), IL-7 (ref. 27) and $\gamma \delta$-TCR signalling ${ }^{28}$ uniformly repressed CCR6 surface expression in $\gamma \delta \mathrm{T} 17$ cells (Fig. 1f and Supplementary Fig. 2b). IL-12 did not impact CCR6 expression, consistent with a reported absence of IL-12R expression by $\gamma \delta \mathrm{T} 17$ cells $^{29}$ (Supplementary Fig. 2b). Activation-induced CCR6 downregulation correlated with induction of activation markers CD69 and CD25 and increased CD44 expression, and occurred in both $\mathrm{V} \gamma 4^{+}$and $\mathrm{V} \gamma 6^{+} \gamma \delta \mathrm{T} 17$ cells (Supplementary Fig. $2 \mathrm{c}, \mathrm{d}$ ). In all in vivo and in vitro systems, $\gamma \delta \mathrm{T} 17$ cells maintained high levels of CCR2 following activation, and virtually all $\gamma \delta \mathrm{T} 17$ cells were CCR ${ }^{+}$(Fig. 1a,c,d,f). Therefore, $\gamma \delta \mathrm{T} 17$ cells are programmed to co-express CCR6 and CCR2 during development, but lose CCR6 expression upon activation.

CCR2 drives $\gamma \delta \mathrm{T} 17$ cell recruitment to inflamed tissues. Tissueinfiltrating $\gamma \delta \mathrm{T} 17$ cells are best understood in the context of cancer and autoimmunity. $\gamma \delta \mathrm{T} 17$ cells infiltrate B16 melanomas and promote tumour growth ${ }^{30,31}$, and infiltrate the CNS at disease onset and exacerbate disease pathogenesis during $\mathrm{EAE}^{1,32}$. How $\gamma \delta \mathrm{T} 17$ cells infiltrate these inflammatory lesions is unknown. We thus used these models to investigate CCR6 and CCR2 function in control of $\gamma \delta \mathrm{T} 17$ cell migration during inflammation. Consistent with the observation that activation induces downmodulation of CCR6 expression, Ccr6-deficiency did not affect $\gamma \delta \mathrm{T} 17$ cell infiltration of B16 melanomas (Fig. 2a,b), nor recruitment to the CNS during EAE onset 

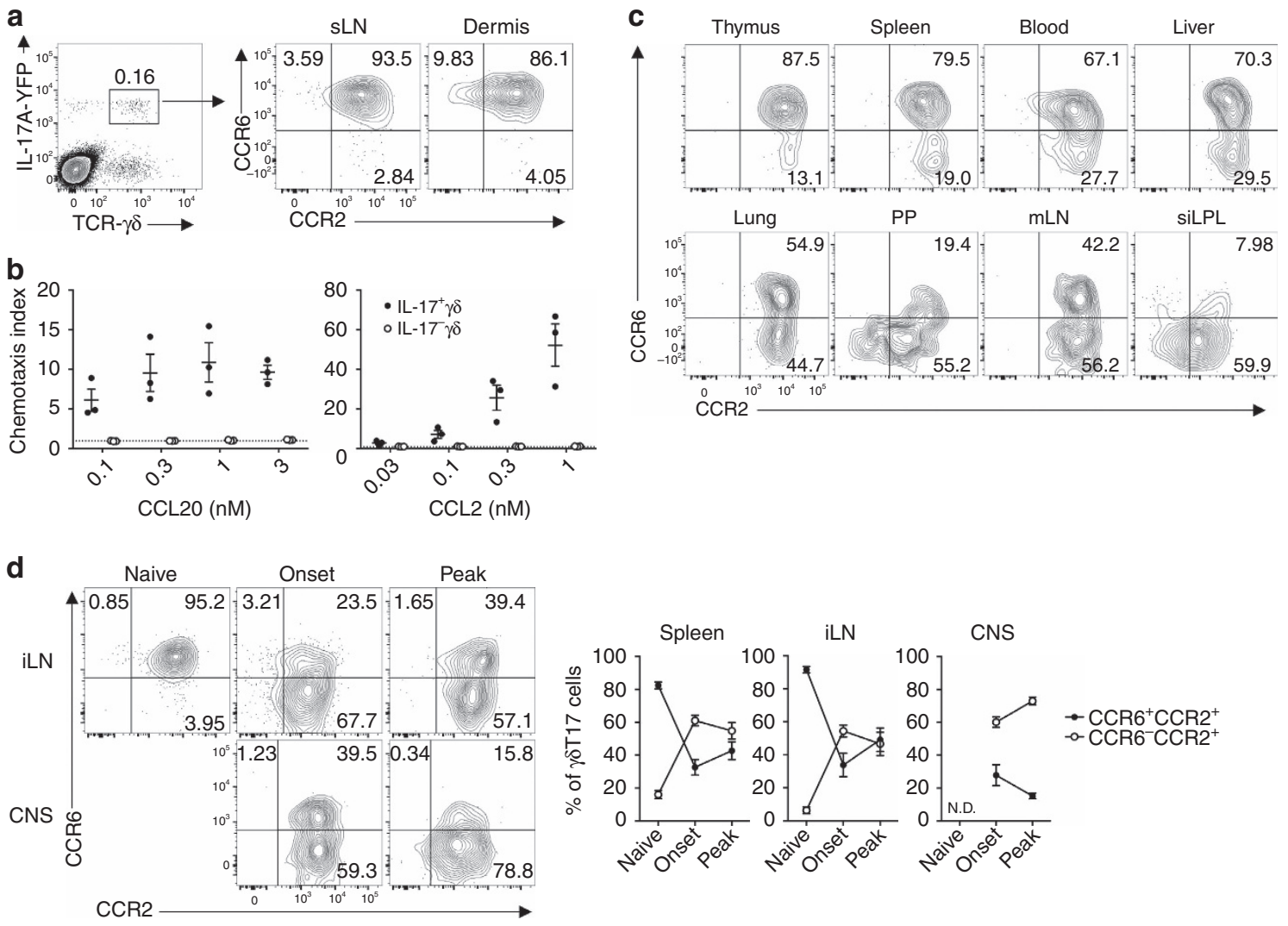

e
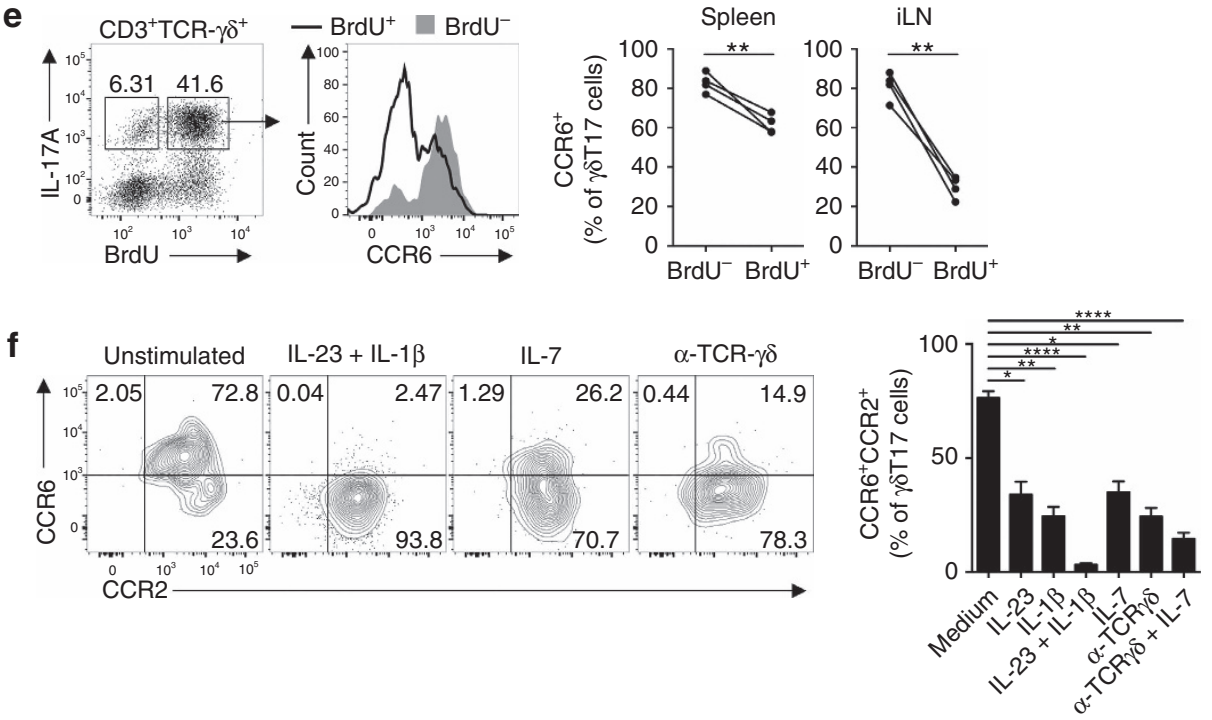

Figure 1 | $\gamma \boldsymbol{\delta} \mathbf{T} 17$ cells downregulate CCR6 upon activation. (a) Representative flow cytometry of CCR6 and CCR2 expression in skin-draining lymph nodes (sLN) and dermal CD3 ${ }^{+} \mathrm{TCR}-\gamma \delta^{+} \mathrm{IL}-17 \mathrm{~A}-\mathrm{YFP}+\gamma \delta \mathrm{T} 17$ cells from $1117 a^{\mathrm{Cre}} \times \operatorname{Ros}_{2} 6^{\mathrm{eYFP}}$ mice $(n=3)$. (b) Ex vivo transwell chemotaxis of $1117 a^{C \text { Cre }} \times$ Rosa26 $6^{\text {YFP }}$ splenic IL-17A $+/-\gamma \delta$ T cells to CCL20 and CCL2 $(n=3)$. (c) Representative flow cytometry of CD45+ $\gamma \delta$ T17 cells from organs of naïve $1117 a^{\text {Cre }} \times$ Rosa26 $6^{\mathrm{eYFP}}$ mice $(n=3)$. $\mathrm{mLN}$, mesenteric lymph node; PP, Peyer's patches; siLPL, small intestinal lamina propria lymphocytes. (d) Representative flow cytometry and quantitation of CCR6 and CCR2 expression by $\gamma \delta$ T17 cells from organs of $1117 a^{\text {Cre }} \times R_{\text {Rosa26 }}{ }^{\text {eYFP }}$ mice either naïve $(n=6)$ or at experimental autoimmune encephalomyelitis (EAE) onset $(n=7)$ or peak $(n=5)$. CNS, central nervous system; iLN, inguinal lymph node; ND, not detected. (e) Representative flow cytometry and quantitation of CCR6 expression by $\gamma \delta \mathrm{T} 17$ cells from wild type (WT) mice given BrdU at d3 post-immunization for EAE, and analysed at $\mathrm{d} 8(n=4)$. (f) Representative flow cytometry and frequency of CCR6 and CCR2 expression by $\gamma \delta T 17$ cells from $1117 a^{C r e} \times$ Rosa26 $6^{\text {YFP }}$ lymphocytes cultured with indicated stimuli for $72 \mathrm{~h}(n=5)$. See also Supplementary Figs 1 and 2 . Mean \pm s.e.m. (a-c) Representative of two experiments. (d,f) Pooled from two experiments. (e) Paired two-tailed Student's $t$-test, $(\mathbf{f})$ one-way paired ANOVA with Dunnett's multiple comparisons test relative to unstimulated control. ${ }^{\star} P<0.05,{ }^{\star \star} P<0.01,{ }^{\star \star \star} P<0.001,{ }^{\star \star \star *} P<0.0001$. 

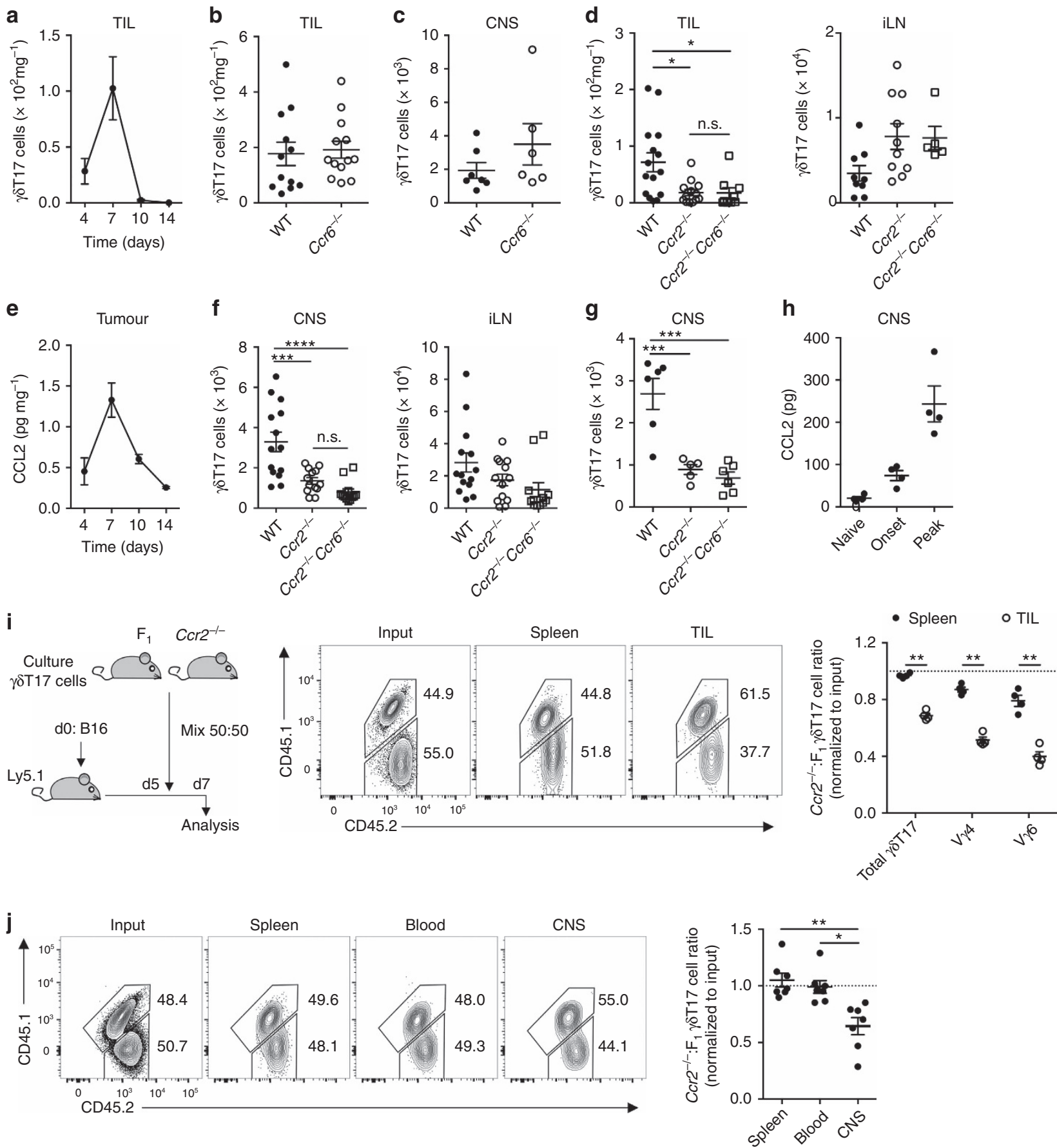

Figure 2 | CCR2 recruits $\gamma \boldsymbol{\delta} \mathbf{T} 17$ cells to inflammatory sites. (a) $\mathrm{CD} 45^{+} \mathrm{CD} 3^{+} \mathrm{TCR} \gamma \delta^{+} \mathrm{IL}-17 \mathrm{~A}^{+} \gamma \delta \mathrm{T} 17$ cell numbers in tumour-infiltrating lymphocytes (TIL) following B16 melanoma challenge ( $n=5$ /time point). (b) $\gamma \delta$ T17 cell numbers in TIL d7 post-challenge with B16 melanoma in wild type (WT) ( $n=12$ ) and $\mathrm{Ccr}^{-/-}$mice $(n=13)$. (c) $\gamma \delta \mathrm{T} 17$ cell numbers in central nervous system (CNS) at experimental autoimmune encephalomyelitis (EAE) onset in WT $(n=7)$ and $\mathrm{Ccr}^{-/-}$mice $(n=6)$. (d) $\gamma \delta \mathrm{T} 17$ cell numbers in TIL and inguinal lymph nodes (iLN) d7 post-challenge with B16 melanoma in WT ( $n=15$ (TIL), 9 (iLN)), $\mathrm{Cr} 2^{-/-}\left(n=13\right.$ (TIL), 10 (iLN)) and $\mathrm{Ccr}^{-/}{ }^{-}-\mathrm{Ccr}^{-/-}$mice $(n=9$ (TIL), 5 (iLN)). (e) ELISA for CCL2 in tumour supernatant from WT mice challenged with B16 melanoma $(n=5 /$ time point). (f) $\gamma \delta$ T17 cell numbers in CNS and iLN at EAE onset in WT $(n=14)$, Ccr2 $-/-(n=13)$ and $\mathrm{Ccr} 2^{-/-} \mathrm{Ccr6} 6^{-/-}$mice $(n=12)$. (g) $\gamma \delta$ T17 cell numbers in CNS at peak disease in WT $(n=6), \mathrm{Ccr}^{-/-}(n=5)$ and $\mathrm{Ccr} 2^{-/-} \mathrm{Ccr} 6^{-/-}$mice $(n=6)$. (h) ELISA for CCL2 in CNS of WT mice with EAE ( $n=4 /$ time point). (i) Ly5.1 mice $(n=4)$ at d5 post-challenge with B16 melanoma were transferred i.v. with in vitro-expanded $\gamma \delta \mathrm{T} 17$ cells from $\mathrm{Ccr} 2^{-/-}\left(\mathrm{CD} 45.2^{+}\right)$and $\mathrm{F}_{1}\left(\mathrm{CD} 45.1^{+} \mathrm{CD} 45.2^{+}\right)$mice. $\mathrm{Ccr} 2^{-/-}: \mathrm{F}_{1}$ total, $\mathrm{V} \gamma 4$ and $\mathrm{V} \gamma 6 \gamma \delta \mathrm{T} 17 \mathrm{cell}$ ratios in spleen and tumours were normalized to input ratio. $\mathrm{V} \gamma 4$ and $\mathrm{V} \gamma 6 \gamma \delta \mathrm{T} 17$ cells were determined by $\mathrm{CD} 3^{\text {bright }}$ gating. Representative flow cytometry of CD45.2 ${ }^{+} \gamma \delta \mathrm{T} 17$ cells at d7 or input. $(\mathbf{j})$ Ly5.1 mice $(n=7)$ at EAE onset were transferred with $\mathrm{F}_{1}$ and $\mathrm{Ccr} 2^{-/-} \gamma \delta \mathrm{T} 17$ cells as in (i). Twenty-four hours later, ratios of $C \mathrm{cr} 2^{-/-}: \mathrm{F}_{1} \gamma \delta \mathrm{T} 17$ cells in spleen, blood and CNS were normalized to input. Representative flow cytometry of CD45.2 ${ }^{+} \gamma \delta \mathrm{T} 17$ cells $24 \mathrm{~h}$ later or input. See also Supplementary Figs 3 and 4. Mean \pm s.e.m. (a,c,e,i) Representative of two experiments. (b,d,f,j) Pooled from two experiments.

$(\mathbf{b}, \mathbf{c})$ Unpaired two-tailed Student's t-test, $(\mathbf{d}, \mathbf{f}-\mathbf{g}, \mathbf{j})$ one-way ANOVA with Bonferroni's multiple comparisons test (paired in $\mathbf{j})$ ), (i) paired two-tailed Student's $t$-test. ${ }^{\star} P<0.05,{ }^{\star \star} P<0.01,{ }^{\star \star \star} P<0.001,{ }^{\star \star \star \star} P<0.0001$. 
(Fig. 2c). Thus, $\gamma \delta$ T17 cell trafficking to inflamed tissues in these settings occurs independently of CCR6.

In contrast, deficiency of $C c r 2$ abrogated $\gamma \delta \mathrm{T} 17$ cell infiltration of B16 melanomas but did not affect their expansion in draining lymph nodes (LNs) (Fig. 2d). CCR2-driven infiltration of $\gamma \delta \mathrm{T} 17$ cells was consistent with upregulation of its major ligand CCL2 in tumours (Fig. 2e). Similar results were found in EAE, where Ccr2-deficiency inhibited $\gamma \delta \mathrm{T} 17$ cell recruitment to the CNS at both onset and peak disease (Fig. 2f,g), time points at which CCL2 was induced in the CNS as reported ${ }^{33}$ (Fig. 2h). CCR2 appeared to operate independently of CCR6 in regulation of $\gamma \delta \mathrm{T} 17$ cell trafficking, as compound deficiency of $\mathrm{Ccr} 6$ and $\mathrm{Ccr} 2$ $\left(\mathrm{Ccr6}^{-/-} \mathrm{Ccr} 2^{-/-}\right)$did not further affect $\gamma \delta \mathrm{T} 17$ cell infiltration in either model (Fig. 2d,f,g).

$\mathrm{Ccr} 2^{-/-} \mathrm{Ccr}^{-}{ }^{-}$mice exhibited enhanced tumour growth, while $\mathrm{Ccr} 2^{-1-}$ and $\mathrm{Ccr}^{-1-} \mathrm{Ccr}^{-1-}$ mice had decreased EAE severity (Supplementary Fig. 3). Therefore, to examine the cell-intrinsic requirements of CCR2 for $\gamma \delta \mathrm{T} 17$ cell migration, we developed a novel in vitro expansion protocol to generate large numbers of purified activated $\gamma \delta \mathrm{T} 17$ cells, which contained both $\mathrm{V} \gamma 4^{+}$and $\mathrm{V} \gamma 6^{+}$subsets and maintained functional CCR2 expression (Supplementary Fig. 4). Equal ratios of in vitroexpanded genetically marked wild type (WT) and $\mathrm{Ccr} 2^{-1-}$ $\gamma \delta \mathrm{T} 17$ cells were co-transferred into B16 melanoma-bearing recipients. While donor $\gamma \delta \mathrm{T} 17$ cells recovered from spleen retained the input ratio, $\mathrm{Ccr} 2^{-/-} \gamma \delta \mathrm{T} 17$ cells did not migrate efficiently to tumours. This observation was true for both $\mathrm{V} 4^{+}$ and ${\mathrm{V} \gamma 6^{+}}^{+}$subsets (Fig. 2i). Similar experiments using the EAE model revealed equivalent WT:Ccr2 $2^{-1-} \gamma \delta \mathrm{T} 17$ cell ratios in spleen and blood but reduced $C c r 2^{-/-} \gamma \delta \mathrm{T} 17$ cell recruitment to the CNS (Fig. 2j). Thus, CCR2, but not CCR6, drives activated $\gamma \delta \mathrm{T} 17$ cell migration to inflammatory sites during B16 melanoma and EAE.

CCR2 is essential for protective $\gamma \delta \mathrm{T} 17$ cell responses. The above models involve $\gamma \delta \mathrm{T} 17$ cell infiltration from circulation, as the CNS and tumours lack resident $\gamma \delta \mathrm{T} 17$ cell populations. However, many inflammatory scenarios implicate tissue-resident $\gamma \delta \mathrm{T} 17$ cells, which survey and rapidly defend against infection at barrier surfaces. The extent to which $\gamma \delta \mathrm{T} 17$ cell migration contributes to host defence during ongoing inflammation is unknown. To investigate whether CCR2 also directs tissue-infiltrating $\gamma \delta \mathrm{T} 17$ cells during infection, we used experimental Streptococcus pneumoniae infection, immunity to which requires $\gamma \delta \mathrm{T} 17$ cells $^{4}$. Accordingly, $\mathrm{Tcrd}^{-1-}$ mice had higher bacterial burden and reduced neutrophils in the nasal wash (NW) than WT at $72 \mathrm{~h}$ post-infection (Fig. 3a,b). S. pneumoniae infection induced $\gamma \delta \mathrm{T} 17$ cell expansion in draining LNs and nasal-associated lymphoid tissue (Fig. 3c). CCL2 was induced in the nasal passages (NPs) upon infection (Fig. 3d), and co-transfer of in vitro-expanded WT and $\mathrm{Ccr} 2^{-/-}$ $\gamma \delta \mathrm{T} 17$ cells into infected mice revealed an intrinsic requirement of CCR2 for $\gamma \delta$ T17 cell accumulation in NP (Fig. 3e). Thus, CCR2 drives circulating $\gamma \delta \mathrm{T} 17$ cell infiltration of mucosal tissue during S. pneumoniae infection.

To elucidate the ability of recruited $\gamma \delta \mathrm{T} 17$ cells to control infection, we transferred purified in vitro-expanded $\gamma \delta \mathrm{T} 17$ cells into $T c r d^{-1-}$ hosts prior to $S$. pneumoniae infection. In this model, tissue-infiltrating $\gamma \delta \mathrm{T} 17$ cells provide the only source of $\gamma \delta$ T-cell-driven protection. Transfer of WT $\gamma \delta \mathrm{T} 17$ cells reduced nasopharyngeal bacterial burden by $\sim 10$-fold, whereas $\mathrm{Ccr} 2^{-/-}$ $\gamma \delta \mathrm{T} 17$ cells completely failed to control infection (Fig. 3f). Hence, CCR2 drives recruitment of protective $\gamma \delta \mathrm{T} 17$ cells to the nasal mucosa during S. pneumoniae infection. Collectively, we conclude that $\gamma \delta \mathrm{T} 17$ cell trafficking to diverse inflamed tissues is critically dependent on CCR2 signalling.
CCR6 regulates homeostatic positioning of $\gamma \delta \mathrm{T} 17$ cells. Expression of CCR6 during $\gamma \delta$ T17 cell thymic development followed by rapid downregulation upon activation suggests that CCR6 plays a more prominent function in regulation of $\gamma \delta \mathrm{T} 17$ cell homeostasis. While CCL20 is induced during inflammation, it is constitutively expressed in barrier tissues including skin, Peyer's patches and large intestine $\mathrm{e}^{34-37}$. Both $\mathrm{Ccr}^{-/-}$and $\mathrm{Ccr2}^{-/-} \mathrm{Ccr6}^{-/-}$mice had markedly reduced number and frequency of $\gamma \delta$ T cells expressing intermediate amounts of CD3/TCR in the dermis $\left(\gamma \delta \mathrm{T}^{\mathrm{lo}}\right)$, a population previously reported to produce IL-17 and distinct from TCR ${ }^{\text {hi }}$ dendritic epidermal T cells ${ }^{22}$ (Fig. 4a). We confirmed that $\gamma \delta \mathrm{T}^{\mathrm{lo}}$ cells were entirely marked by eYFP in $I l 17 a^{\text {Cre }} \times$ Rosa $26^{\text {PYPP }}$ mice, despite negligible IL-17A production following ex vivo restimulation (Supplementary Fig. 5a). In contrast to a previous report ${ }^{10}$, Ccr6-deficiency reduced the number of both $\mathrm{V} \gamma 4^{+}$and $\mathrm{V} \gamma 4^{-}$ $\left(\mathrm{V} \gamma 6^{+}\right) \gamma \delta \mathrm{T}^{\mathrm{lo}}$ cells, although the ratio was skewed slightly towards ${\mathrm{V} \gamma 6^{+}}^{+}$cells (Fig. 4b). Examination of other organs revealed that deficiency in Ccr2 had no effect on $\gamma \delta \mathrm{T} 17$ cell homeostasis, while Ccr6-deficiency increased $\gamma \delta \mathrm{T} 17$ cells in the peritoneal cavity (Supplementary Fig. 5b). We conclude that CCR6 regulates dermal $\gamma \delta \mathrm{T} 17$ cell residence.

To determine whether CCR6 drives recruitment of circulating $\gamma \delta$ T17 cells into dermis, we transferred unstimulated WT or $\mathrm{Ccr6}^{-/-}$lymphocytes into naïve mice and tracked their accumulation in dermis. Transferred WT $\gamma \delta \mathrm{T} 17$ cells were substantially enriched in dermis, demonstrating that $\gamma \delta \mathrm{T} 17$ cells can constitutively populate the skin from circulation. In contrast, $\mathrm{Ccr}^{-/-} \gamma \delta \mathrm{T} 17$ cells were defective in infiltration of dermis and pooled in the blood (Fig. 4c). In support of earlier results, both $\mathrm{V} \gamma 4^{+}$and $\mathrm{V} \gamma 4^{-} \gamma \delta \mathrm{T} 17$ cells were recruited to the dermis, the ratio of which was unaltered by Ccr6 deficiency, suggesting both populations are dependent on CCR6 for circulation-to-dermis trafficking (Fig. 4c). While constitutive expression of CCL20 in epidermis was reported, whether it is expressed in uninflamed dermis is unclear ${ }^{34,38}$. We found that $C c l 20$ was constitutively expressed in the dermis by an uncharacterized $\mathrm{CD} 31^{-}$ $\mathrm{CD} 90^{-} \mathrm{CD} 140 \alpha^{-}$stromal population (Fig. 4d). Thus, CCR6 directs homeostatic recruitment of $\gamma \delta \mathrm{T} 17$ cells from circulation into dermis.

IRF4 and BATF regulate CCR6 expression in $\gamma \delta \mathrm{T} 17$ cells. The downregulation of CCR6 upon $\gamma \delta$ T17 cell activation is surprising, as $\mathrm{T}$ cells typically upregulate inflammatory chemokine receptors upon activation. Consequently we investigated the underlying mechanism regulating this process. Ccr6 transcript levels were reduced by approx. fourfold in $\gamma \delta \mathrm{T} 17$ cells within $24 \mathrm{~h}$ of stimulation, whereas $\mathrm{Ccr} 2$ expression was maintained (Fig. 5a and Supplementary Fig. 6a). This indicated that CCR6 expression is transcriptionally regulated during $\gamma \delta \mathrm{T} 17$ cell activation. We thus examined expression of transcription factors previously implicated directly or indirectly in control of Ccr6 expression, including ROR $\gamma \mathrm{t}^{17}$, IRF4 (ref. 39), IRF8 (refs 40,41), Blimp1 (refs 39,42), BATF ${ }^{43}$ and T-bet and Eomes ${ }^{18}$. Rorc (ROR $\gamma \mathrm{t}$ ) was highly expressed in resting $\gamma \delta \mathrm{T} 17$ cells but was downregulated by $24 \mathrm{~h}$ of activation. Batf and Prdm1 (Blimp1) were rapidly upregulated by $24 \mathrm{~h}$, while Irf8 and Irf4 were upregulated by $48 \mathrm{~h}$, although Irf4 was already present in resting $\gamma \delta \mathrm{T} 17$ cells. Expression of Eomes and Tbx21 (T-bet) at rest or following activation was minimal (Fig. 5b and Supplementary Fig. 6b). Therefore, we tested whether ROR $\gamma \mathrm{t}$, IRF4, BATF, Blimp1 or IRF8 repressed Ccr6 expression during $\gamma \delta \mathrm{T} 17$ cell activation.

The similar expression kinetics and known Ccr6 regulatory activity of ROR $\gamma \mathrm{t}$ presented the possibility that its downregulation may result in loss of CCR6 expression. To test this, 
a

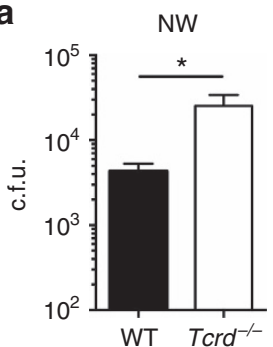

e

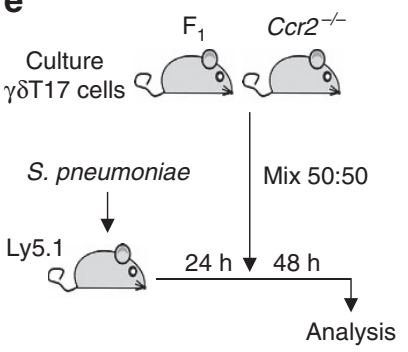

b

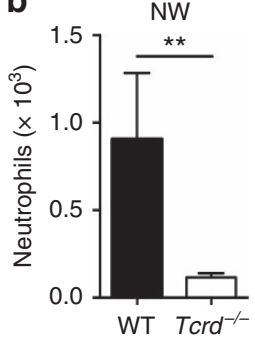

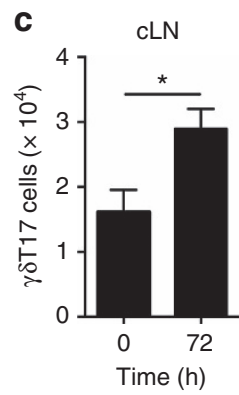
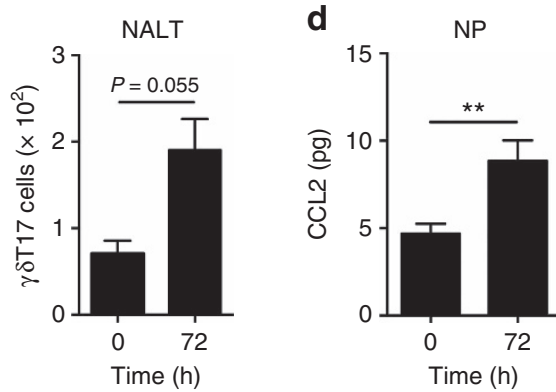
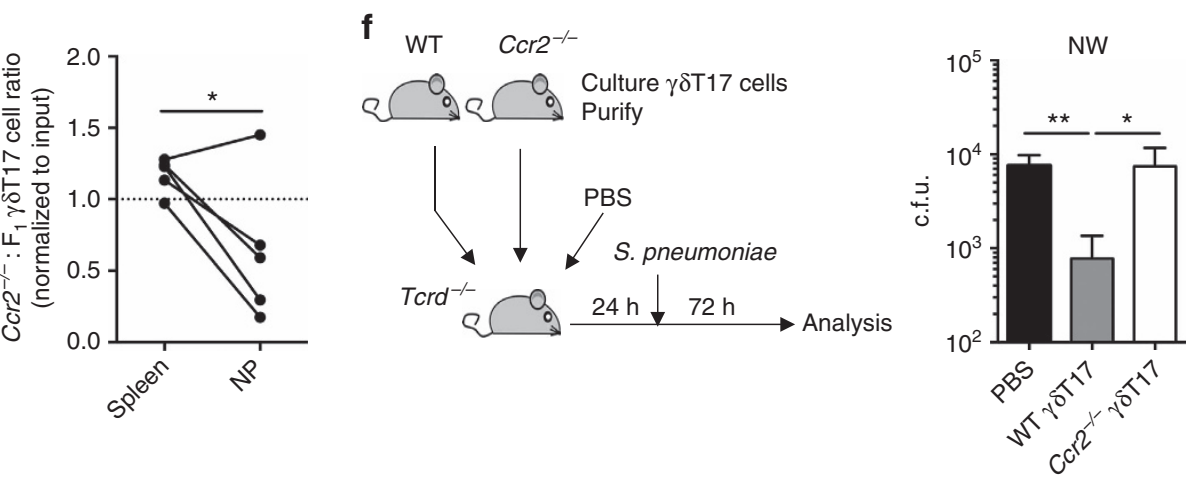

Figure 3 | CCR2 drives protective $\boldsymbol{\gamma} \boldsymbol{\delta} \mathbf{T 1 7}$ cell responses. (a) Colony-forming units (c.f.u.) and (b) $\mathrm{CD} 45^{+}$CD11b ${ }^{+}$Ly6G ${ }^{+}$neutrophils recovered from nasal wash (NW) of wild type (WT) $(n=9)$ and $\operatorname{Tcrd}^{-/-}$mice $(n=10) 72 \mathrm{~h}$ post-infection with S. pneumoniae. (c) $\gamma \delta \mathrm{T} 17$ cell numbers in cervical lymph node (cLN) and nasal-associated lymphoid tissue (NALT) and (d) ELISA for CCL2 in digested nasal passage (NP) supernatant in unimmunized mice $(n=7)$ and at $72 \mathrm{~h}$ post-S. pneumoniae infection $(n=13)$. (e) Ly5.1 mice $(n=5) 24 \mathrm{~h}$ post-S. pneumoniae infection were transferred i.v. with expanded $\gamma \delta \mathrm{T} 17$ cells from $\mathrm{Ccr} 2^{-/-}\left(\mathrm{CD} 45.2^{+}\right)$and $\mathrm{F}_{1}\left(\mathrm{CD} 45.1^{+} \mathrm{CD} 45.2^{+}\right)$mice. The $\mathrm{Ccr} 2^{-/-}: \mathrm{F}_{1} \gamma \delta \mathrm{T} 17$ cell ratio in spleen and NP was normalized to input ratio. (f) Twenty-four hours prior to S. pneumoniae infection, $\mathrm{Tcrd}^{-/-}$hosts received PBS $(n=8)$ or expanded and purified $\gamma \delta \mathrm{T} 17$ cells from WT $(n=9)$ or $\mathrm{Ccr}^{-/-}(n=7)$ mice. c.f.u. recovered from NW $72 \mathrm{~h}$ post-infection. Mean \pm s.e.m. (a-d) Pooled from two experiments. (a,b) Mann-Whitney test, $(\mathbf{c}, \mathbf{d})$ unpaired two-tailed Student's $t$-test, $(\mathbf{e})$ paired two-tailed Student's $t$-test, (f) Kruskal-Wallis test with Dunn's multiple comparisons test. ${ }^{\star} P<0.05$, ${ }^{\star *} P<0.01$.

we retrovirally forced Rorc expression in in vitro-expanded $\gamma \delta \mathrm{T} 17$ cells (Fig. 5c). However, this failed to alter CCR6 expression even in the highest GFP-expressing cells, suggesting that ROR $\gamma \mathrm{t}$ downregulation is not required for repression of CCR6 in activated $\gamma \delta \mathrm{T} 17$ cells (Fig. $5 \mathrm{~d}$ ).

To determine whether IRF4, BATF, IRF8 or Blimp1 actively repress Ccr6 expression, we cultured genetically-marked WT and transcription factor-deficient splenocytes with IL-23 and IL-1 $\beta$. $\gamma \delta$ T17 cells were present in all strains although at differing frequencies, and homeostatic CCR6 expression was comparable to WT (Supplementary Fig. 6c). IRF4- and BATF-deficient $\gamma \delta \mathrm{T} 17$ cells were intrinsically defective in both proliferation and CCR6 downregulation upon stimulation (Fig. 5e). IRF8 and Blimp1 were not required for these processes, although Blimp1 appeared to moderately promote CCR2 expression in activated $\gamma \delta \mathrm{T} 17$ cells (Supplementary Fig. 6d). Irf4 $4^{-/-}$and Batf ${ }^{-/-}$ $\gamma \delta \mathrm{T} 17$ cells exhibited comparable surface expression of IL-23R and IL-1R1 to WT cells, indicating that maintained CCR6 expression was likely due to defective signalling downstream of IL-23 and IL-1 $\beta$ stimulation (Supplementary Fig. 7a). Analysis of our and others' ChIP-Seq datasets in T cells ${ }^{43-45}$ revealed binding of IRF4 and BATF to a shared site in the Ccr6 promoter (Supplementary Fig. 7b), suggesting that these factors cooperatively and directly repress Ccr 6 in $\gamma \delta \mathrm{T} 17$ cells. To assess whether defective proliferation in absence of IRF4 or BATF was the cause of impaired CCR6 downregulation, dye-labelled WT splenocytes were pre-treated with proliferation inhibitor mitomycin $\mathrm{C}$ prior to stimulation. Although proliferation was effectively blocked, CCR6 downregulation still occurred upon mitomycin $\mathrm{C}$ treatment, suggesting that proliferation and CCR6 downregulation are coincident but independent (Fig. 5f). Together, these data indicate that activation-induced CCR6 downregulation in $\gamma \delta$ T17 cells is promoted by IRF 4 and BATF, and is largely uncoupled from proliferation.

Loss of CCR6 promotes $\gamma \delta \mathrm{T} 17$ cell homing to inflamed tissues. Given the constitutive expression of CCL20 in mucocutaneous sites, we hypothesized that repression of CCR6 during activation enables homing of $\gamma \delta \mathrm{T} 17$ cells toward inflammatory lesions by preventing their accumulation in uninflamed skin. To test this, we first compared the trafficking of in vitro-activated WT $\gamma \delta \mathrm{T} 17$ cells with resting WT and $C c r 6^{-/-} \gamma \delta \mathrm{T} 17$ cells upon transfer into unimmunized hosts. Activated WT $\gamma \delta \mathrm{T} 17$ cells demonstrated the same defect in homing to the dermis as resting $\mathrm{Ccr6}^{-/-}$ $\gamma \delta \mathrm{T} 17$ cells, and both pooled in blood compared to resting WT $\gamma \delta \mathrm{T} 17$ cells (Fig. 6a). $\gamma \delta \mathrm{T} 17$ cells lack CD62L and CCR7 expression, and traffic from skin to sLNs in a CCR7-independent manner ${ }^{12}$. Thus $\gamma \delta \mathrm{T} 17$ cell entry to sLNs following adoptive transfer likely occurs via afferent lymph draining from dermis. In keeping with this idea, resting $C \mathrm{cr} 6^{-/-}$or in vitro-activated WT $\gamma \delta$ T17 cells, impaired in their ability to home to uninflamed skin, also accumulated less than resting WT $\gamma \delta \mathrm{T} 17$ cells in sLNs (Fig. 6a). These data are consistent with the notion that activation switches off $\gamma \delta \mathrm{T} 17$ cell homeostatic circulation patterns, enabling directed migration toward inflammatory cues.

To investigate this proposal directly, we studied the migratory patterns of in vitro-activated $\gamma \delta \mathrm{T} 17$ cells retrovirally forced to maintain CCR6 expression. Infection with $C c r 6^{\text {tg }}$ virus restored CCR6 expression in activated $\gamma \delta \mathrm{T} 17$ cells, which regained the 
a
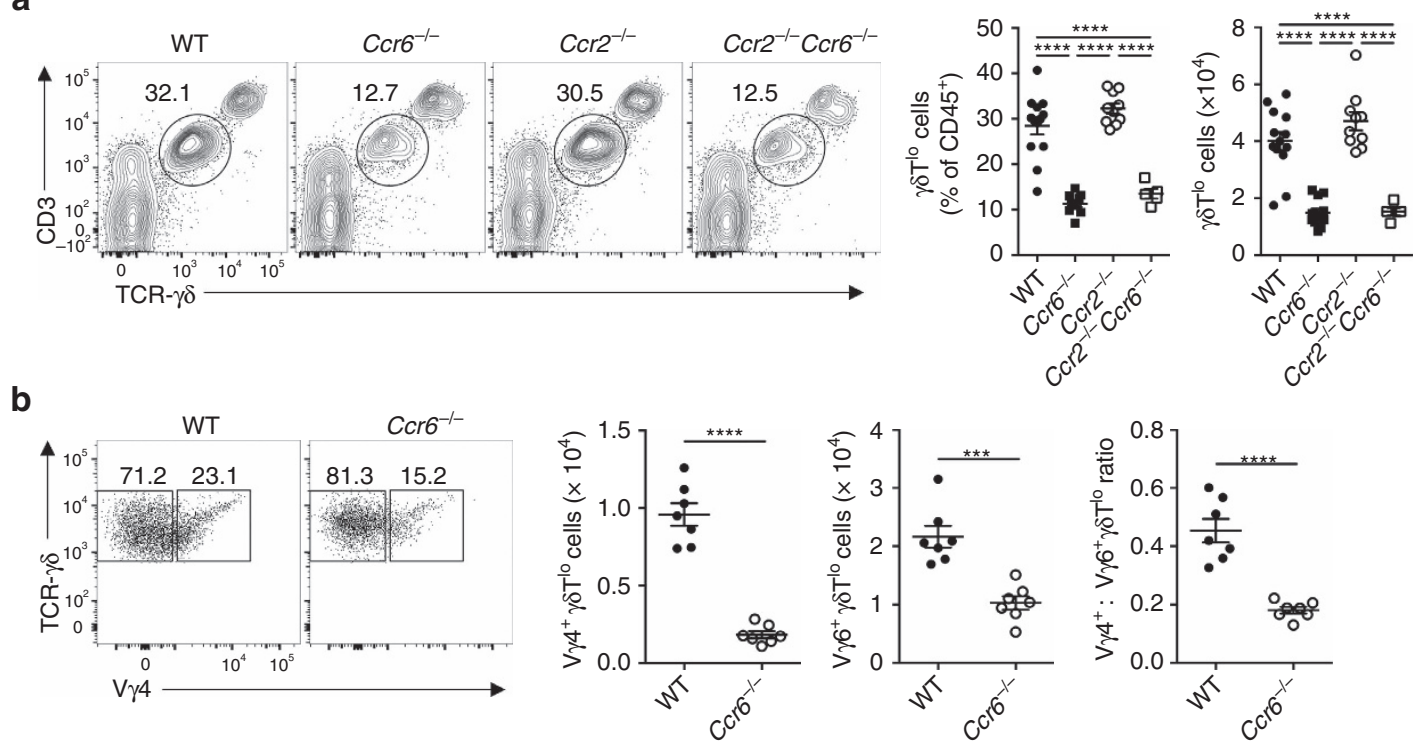

C
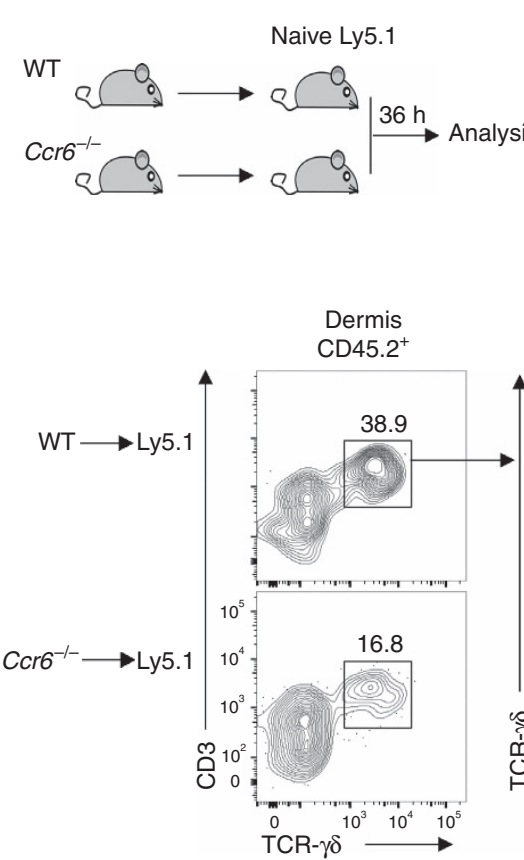
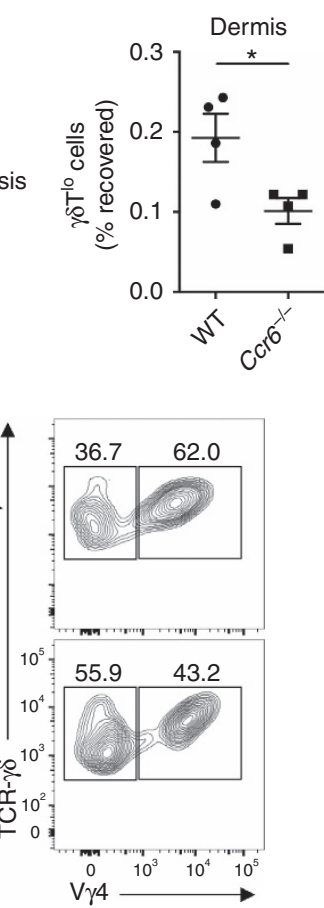
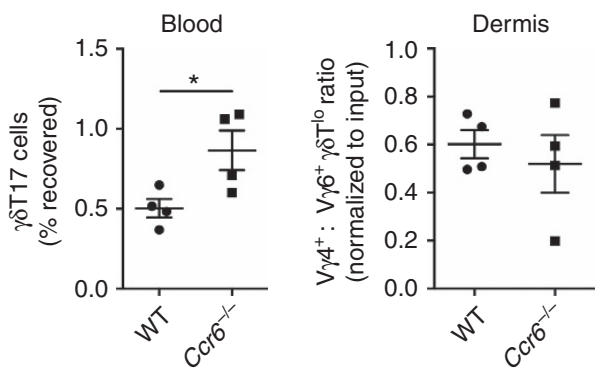

d

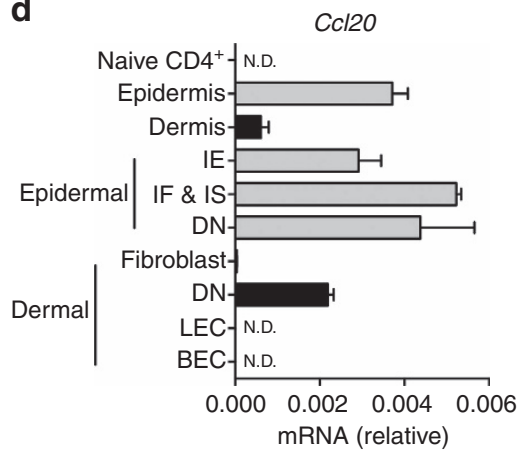

Figure 4 | CCR6 regulates homeostatic $\gamma \delta$ T17 cell recruitment to dermis. (a) Representative flow cytometry and quantitation of $C D 45^{+} \mathrm{CD} 3^{l 0} \mathrm{TCR}-\gamma \delta^{\mathrm{lo}}$ $\left(\gamma \delta \mathrm{T}^{\mathrm{lo}}\right)$ cells from ear skin dermis of naïve wild type (WT) $(n=13), \mathrm{Ccr6}^{-/-}(n=11), \mathrm{Ccr}^{-/}-(n=10)$ and $\mathrm{Ccr} 2^{-/-} \mathrm{Ccr6} \sigma^{-/-}$mice $(n=5)$.

(b) Representative flow cytometry of $\mathrm{V} \gamma 4$ expression by dermal $\gamma \delta T^{\text {lo }}$ cells and quantitation of $\mathrm{V}_{\gamma} 4^{+}$and $\mathrm{V} \gamma 4^{-} \gamma \delta \mathrm{T}^{\mathrm{lo}}$ cells in dermis of WT and $C \mathrm{cr} 6^{-/-}$ mice ( $n=7 /$ group). (c) WT or $\mathrm{Ccr}^{-/-}$lymphocytes were transferred i.v. into naïve Ly5.1 mice ( $n=4 /$ group). After $36 \mathrm{~h}$, number of CD45.2 ${ }^{+}$ $\gamma \delta \mathrm{T}^{\mathrm{lo}} / \gamma \delta \mathrm{T} 17$ cells recovered was expressed as \% of number transferred. Representative flow cytometry of dermal CD45.2 ${ }^{+}$cells and quantitation of

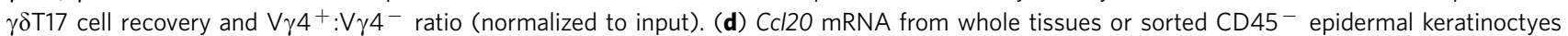

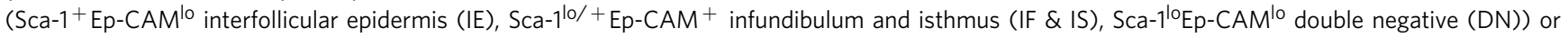
CD45- dermal populations (CD31-CD90 ${ }^{-}$CD140 $\alpha+$ fibroblast, gp38 ${ }^{+} \mathrm{CD} 31^{+}$lymphatic endothelial cells (LEC), gp38 ${ }^{\circ} \mathrm{CD} 31^{+}$blood endothelial cells (BEC), $C D 31^{-}$CD90-CD140 $\alpha^{-}$double negative (DN)) from naïve WT mice (pooled from 5 mice/experiment). ND, not detected. See also Supplementary Fig. 5. Mean \pm s.e.m. (a,d) Pooled from three experiments, (c) representative of two similar experiments. (a) One-way ANOVA with Bonferroni's multiple comparisons test, $(\mathbf{b}, \mathbf{c})$ unpaired two-tailed Student's $t$-test. ${ }^{\star} P<0.05,{ }^{\star \star} P<0.01,{ }^{\star \star \star} P<0.001,{ }^{\star \star \star \star} P<0.0001$.

ability to migrate toward CCL20 (Fig. 6b,c). Genetically marked control- and $C c r 6^{\text {tg }}$-transduced $\gamma \delta$ T17 cells were mixed 50:50 and transferred into B16 melanoma-bearing recipients. While the input ratio of transferred $\mathrm{GFP}^{-}$cells was maintained in all examined organs as expected, among $\mathrm{GFP}^{+}$cells, $C c r 6^{\mathrm{tg}} \gamma \delta \mathrm{T} 17$ cells were enriched in the dermis but deficient in tumours (Fig. 6d). Similar results were observed during S. pneumoniae infection: $C c r 6^{\mathrm{tg}} \gamma \delta \mathrm{T} 17$ cells were selectively deficient at homing to NP, but accumulated to a greater extent than controltransduced cells in uninflamed dermis (Fig. 6e). Ccr $6^{\mathrm{tg}} \gamma \delta \mathrm{T} 17$ 

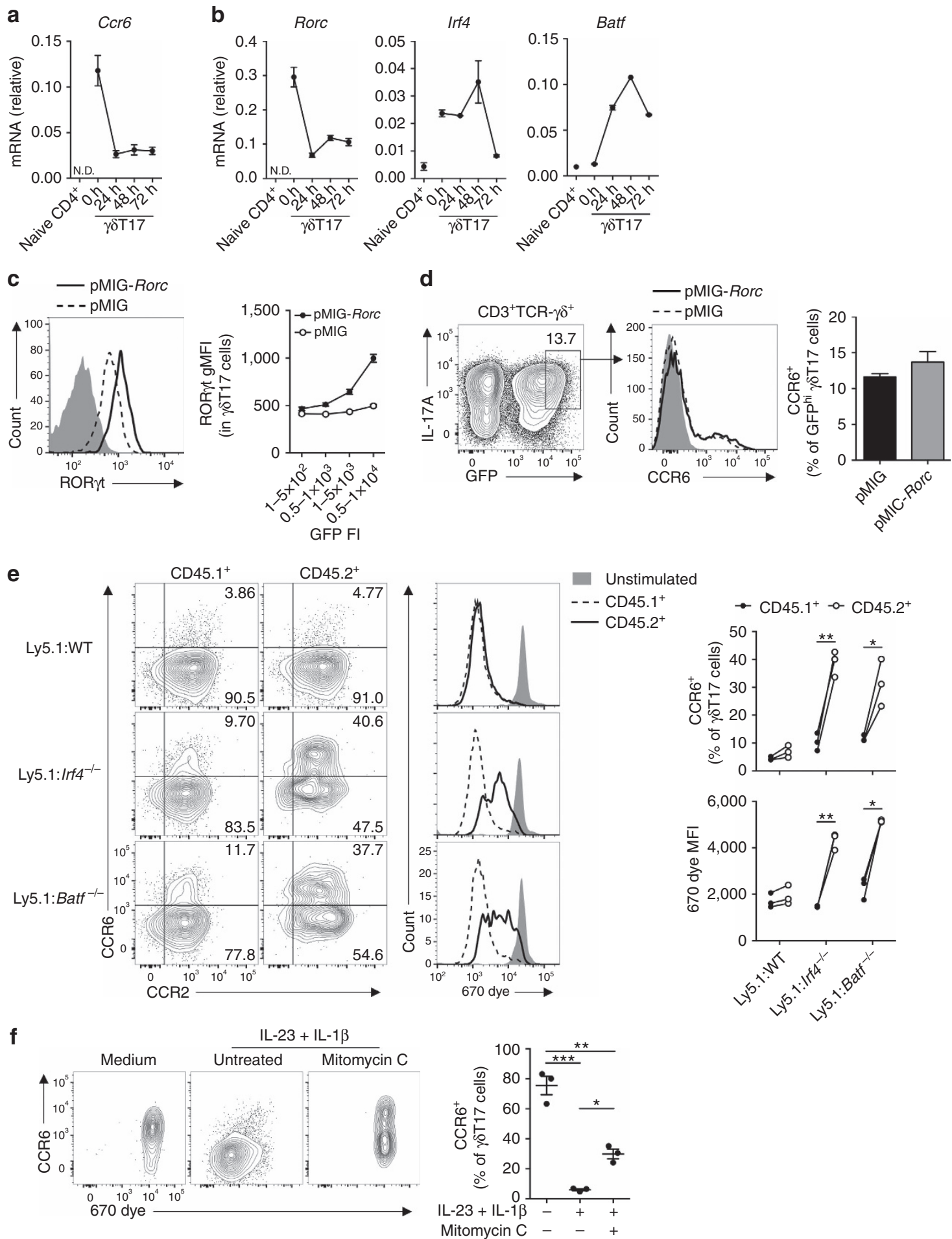

Figure 5 | IRF4 and BATF promote CCR6 downregulation in $\gamma \delta$ T17 cells. (a) Ccr6 and (b) transcription factor mRNA in sorted $\gamma \delta T 17$ cells from $1117 a^{C r e} \times$ Rosa26 $6^{\mathrm{eYF}}$ lymphocytes ex vivo or cultured with IL-23/IL-1 $\beta$ for indicated times (pooled from 5 to 7 mice). ND, not detected. (c,d) Expanded $\gamma \delta \mathrm{T} 17$ cells $(n=3)$ were transduced with empty PMIG or pMIG-Rorc retrovirus. (c) Representative flow cytometry of ROR $\gamma \mathrm{t}$ expression in GFPhi $\gamma \delta \mathrm{T} 17$ cells (gated as in $\mathbf{d}$ ), relative to isotype (grey) and geometric mean fluorescence intensity ( $\mathrm{GMFI}$ ) relative to GFP fluorescence intensity (FI).

(d) Representative flow cytometry of CCR6 expression and quantitation in GFPhi $\gamma \delta \mathrm{T} 17$ cells. (e) Splenocytes from Ly5.1 and either wild type (WT), Irf $4^{-/-}$or Batf ${ }^{-/-}$mice were 670 dye-labelled, mixed 50:50 and stimulated with IL-23/IL-1 $\beta$ for $72 \mathrm{~h}$. Representative flow cytometry and quantitation of CCR6 expression and proliferation in CD45.1 ${ }^{+}$or CD45.2 ${ }^{+} \gamma \delta \mathrm{T} 17$ cells $(n=3 /$ group). (f) Representative flow cytometry and quantitation of CCR6 expression by 670 dye-labelled $\gamma \delta T 17$ cells from WT splenocytes cultured with IL-23/IL-1 $\beta$ for $72 \mathrm{~h}$ with/without mitomycin C pre-treatment $(n=3)$. See also Supplementary Figs 6 and 7. (a,b) Mean \pm s.d., (c-f) Mean \pm s.e.m. (a-f) Representative of two similar experiments. (d,e) Paired two-tailed Student's $t$-test, (f) one-way paired ANOVA with Bonferroni's multiple comparisons test. ${ }^{\star} P<0.05,{ }^{\star \star} P<0.01,{ }^{\star \star \star} P<0.001$. 
cells also homed less efficiently to the CNS during EAE, although subcutaneous complete Freund's adjuvant immunization precluded analysis of homing to uninflamed skin in this model
(Fig. 6f). Together, these experiments demonstrated that activated $\gamma \delta \mathrm{T} 17$ cells with forced CCR6 expression were recruited to uninflamed dermis at the expense of homing to inflamed tissue.
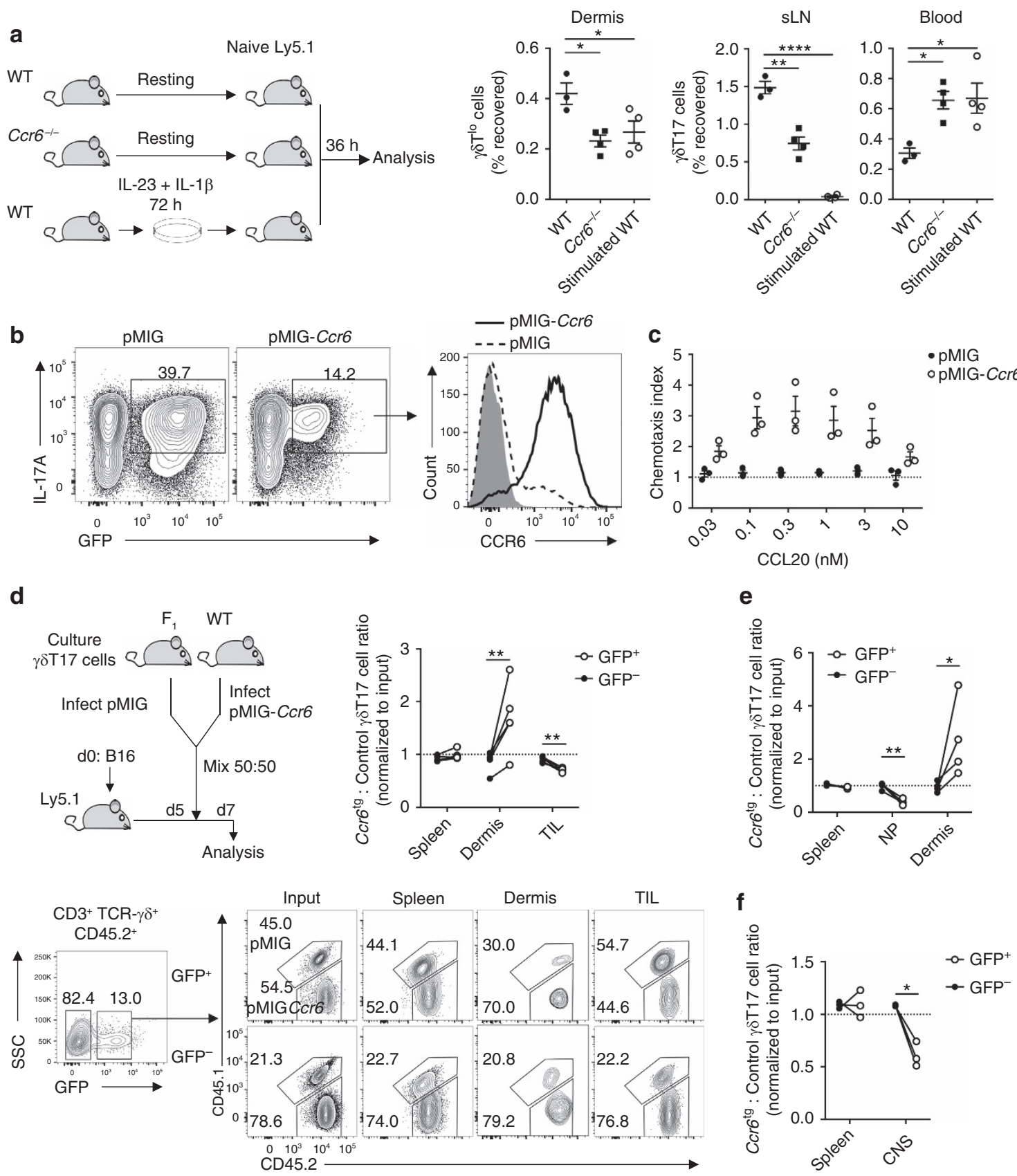

Figure 6 | CCR6 downregulation by $\boldsymbol{\gamma} \boldsymbol{\delta}$ T17 cells enhances migration to inflamed tissue. (a) Resting lymphocytes from wild type (WT) ( $n=3$ ) or $\mathrm{Ccr6}^{-/-}(n=4)$ mice, or WT lymphocytes stimulated with IL-23/IL-1 $\beta$ for $72 \mathrm{~h}(n=4)$ were transferred i.v. into separate naïve Ly5.1 hosts. After $36 \mathrm{~h}$, number of CD45.2 ${ }^{+} \gamma \delta \mathrm{T}^{\mathrm{lo}} / \gamma \delta \mathrm{T} 17$ cells recovered was expressed as \% of number transferred. sLN, skin-draining lymph node. (b) Representative flow cytometry for CCR6 expression by GFP ${ }^{+}$in vitro-expanded $\gamma \delta T 17$ cells transduced with empty pMIG or pMIG-Ccr6, relative to isotype (grey) ( $n=3$ ). (c) Chemotaxis of GFP ${ }^{+} \gamma \delta \mathrm{T} 17$ cells transduced as in $(\mathbf{b})$ to $\mathrm{CCL} 20(n=3)$. (d) In vitro-expanded $\gamma \delta \mathrm{T} 17$ cells from $\mathrm{F}_{1}\left(\mathrm{CD} 45.1^{+} \mathrm{CD} 45.2^{+}\right)$or WT $\left(C D 45.2^{+}\right)$mice were transduced with empty pMIG or pMIG-Ccr6, respectively. Equal numbers of mixed GFP ${ }^{+}$cells were transferred i.v. into Ly5.1 mice challenged with B16 melanoma 5 days prior and analysed at $d 7(n=5)$. Representative flow cytometry and ratio of recovered $F_{1}$ to WT $\gamma \delta T 17$ cells within transduced $\left(\mathrm{GFP}^{+}\right)$and untransduced (GFP-) populations. Recovered values were normalized to input values. TIL, tumour-infiltrating lymphocytes. $(\mathbf{e}, \mathbf{f})$ In vitro-expanded $\gamma \delta \mathrm{T} 17$ cells from WT or $\mathrm{F}_{1}$ mice were transduced with empty pMIG or pMIG-Ccr6, respectively. Equal numbers of mixed GFP ${ }^{+}$cells were transferred i.v. into Ly5.1 mice either (e) $24 \mathrm{~h}$ post-infection with S. pneumoniae $(n=4)$ or $(\mathbf{f})$ at experimental autoimmune encephalomyelitis (EAE) onset $(n=3)$ and organs were analysed $48 \mathrm{~h}$ later. Ratio of recovered WT to $\mathrm{F}_{1} \gamma \delta \mathrm{T} 17$ cells within transduced $\left(\mathrm{GFP}^{+}\right)$and untransduced $\left(\mathrm{GFP}^{-}\right)$ populations, normalized to input values. CNS, central nervous system; NP, nasal passage. Mean \pm s.e.m. (a) Representative of three similar experiments, $(\mathbf{b}, \mathbf{d})$ representative of two experiments. (a) One-way ANOVA with Dunnett's multiple comparisons test relative to resting WT $\gamma \delta T 17$ cells, (d-f) paired two-tailed Student's $t$-test. ${ }^{\star} P<0.05,{ }^{\star \star} P<0.01,{ }^{\star \star \star} P<0.001,{ }^{\star \star \star \star} P<0.0001$. 
Thus, CCR6 downregulation promotes $\gamma \delta \mathrm{T} 17$ cell migration to inflammatory sites.

\section{Discussion}

In the present study we define the molecular regulation of $\gamma \delta \mathrm{T} 17$ cell trafficking between resting and activated states. Our data are consistent with a model in which $\gamma \delta \mathrm{T} 17$ cells are imprinted with expression of both CCR6 and CCR2 during thymic development. CCR6 coordinates steady-state recruitment of circulating $\gamma \delta \mathrm{T} 17$ cells into the dermis, where CCL20 is constitutively expressed, thus orchestrating their homeostatic recirculation. Upon activation, $\gamma \delta$ T17 cells rapidly downregulate CCR6 in an IRF4- and BATF-dependent manner. CCR2 expression is maintained and drives homing of activated $\gamma \delta \mathrm{T} 17$ cells to inflamed tissue during autoimmunity, cancer and infection. CCR6 downregulation is required to promote optimal recruitment of activated $\gamma \delta \mathrm{T} 17$ cells to inflamed tissue, by preventing their diversion and sequestration into uninflamed skin. These data identify a novel mode of lymphocyte trafficking that facilitates both $\gamma \delta \mathrm{T} 17$ cell innate-like surveillance of host tissues and their rapid recruitment to distal sites of ongoing inflammation.

Our data demonstrate that CCR6 coordinates homeostatic recirculation of ${\mathrm{V} \gamma 4^{+}}^{+}$and $\mathrm{V} \gamma 6^{+} \gamma \delta \mathrm{T} 17$ cells through blood, skin and sLNs. Given that $\gamma \delta \mathrm{T} 17$ cells likely populate sLNs via afferent lymph ${ }^{12,14}$, our data suggest that entry is contingent on first trafficking through the dermis, as Ccr6-deficient $\gamma \delta \mathrm{T} 17$ cells fail to localize to both organs. Thus, in addition to driving infiltration of skin, CCR6 ultimately regulates $\gamma \delta \mathrm{T} 17$ cell homing to sLNs. These findings complement a recent report that CCR6 positions sLN ${\mathrm{V} \gamma 4^{+}}^{+} \delta \mathrm{T} 17$ cells in the subcapsular sinus ${ }^{11}$. Our findings are also in agreement with previous reports of steady-state $\gamma \delta \mathrm{T} 17$ cell circulation, although we show that in addition to $\mathrm{V} \gamma 4^{+}, \mathrm{V} \gamma 6^{+} \gamma \delta \mathrm{T} 17$ cells also undergo constitutive trafficking ${ }^{10,13,14}$. While most $\mathrm{V} \gamma 4^{+} \gamma \delta \mathrm{T} 17$ cells in sLNs do not recirculate within a 2 -week period, approximately $25 \%$ undergo extensive circulation ${ }^{11}$. The non-recirculating population of sLN $\gamma \delta \mathrm{T} 17$ cells is likely those positioned in interfollicular zones and subcapsular sinus, which were proposed to scan for sLN-invading microbes $^{11,46}$. However, the function of the recirculating population of $\gamma \delta \mathrm{T} 17$ cells is unclear. As $\gamma \delta \mathrm{T} 17$ cells do not need to scan sLNs for antigen like conventional $\mathrm{T}$ cells, why they adopt a constitutive CCR6-dependent circulation loop between tissues and sLNs remains to be resolved.

We found that programmed expression of CCR 2 equips $\gamma \delta \mathrm{T} 17$ cells with the ability to rapidly home from circulation into diverse inflammatory environments. Our description of CCR2-driven $\gamma \delta \mathrm{T} 17$ cell infiltration of the autoimmune CNS reflects other reports during psoriasis and arthritis ${ }^{15,20}$. Additionally, CCR2mediated infiltration of both $\mathrm{V} \gamma 4^{+}$and $\mathrm{V} \gamma 6^{+} \gamma \delta \mathrm{TT} 17$ cells into B16 melanomas suggests that this axis is a universal inflammatory homing signal for $\gamma \delta \mathrm{T} 17$ cells. Our data reveal a redundant function for CCR6 in these processes, due to its immediate downregulation upon $\gamma \delta \mathrm{T} 17$ cell activation. However, these data are inconsistent with reports of CCR6-driven migration of $\gamma \delta \mathrm{T} 17$ cells during skin and liver inflammation ${ }^{19,47}$. Tissue-specific signals directing maintained CCR6 expression in activated $\gamma \delta \mathrm{T} 17$ cells in these particular scenarios could possibly explain discrepancies between these reports and our data, although this requires further investigation. The function of tissue-infiltrating $\gamma \delta$ T17 cells during inflammation in barrier tissues, where a resident $\gamma \delta \mathrm{T} 17$ cell population already exists, is unclear. This phenomenon was previously reported during psoriasis, although did not appear to affect disease ${ }^{14,48}$. Here, we show that $\gamma \delta \mathrm{T} 17$ cells expand in draining LNs and infiltrate nasal mucosa via CCR2 during bacterial infection. In absence of endogenous $\gamma \delta \mathrm{T}$ cells, transferred circulating $\gamma \delta \mathrm{T} 17$ cells are able to control infection in a CCR2-dependent manner. Thus, we propose that $\mathrm{LN}$-expanded $\gamma \delta \mathrm{T} 17$ cells home to lesions via CCR2 to supplement the local $\gamma \delta \mathrm{T} 17$ cell pool during ongoing tissue inflammation.

Along with our previous work, this study identifies a shared chemokine receptor program used by IL-17-producing cells. We show that like Th17 cells ${ }^{18}, \gamma \delta$ T17 cells express CCR6 early during their effector program, but lose CCR6 expression via IL-23 signalling during ongoing inflammation. Instead, CCR2 is the defining IL-17-program inflammatory homing signal. Whether CCR6 repression in Th17 cells occurs to disrupt barrier tissue-homing and promote recruitment to inflamed tissue, as we show in $\gamma \delta \mathrm{T} 17$ cells, is unclear. Despite $\gamma \delta \mathrm{T} 17$ cell development occurring independently of IRF4 and $\mathrm{BATF}^{49,50}$, we report that these factors suppress Ccr6 expression in $\gamma \delta \mathrm{T} 17$ cells upon IL-23- and IL-1 $\beta$-driven activation. This is likely to be cooperative, as has been shown during Th17 cell development ${ }^{43}$. Moreover, we identified a common binding site for IRF4 and BATF in the Ccr6 promoter, suggesting that repression of $\mathrm{Ccr} 6$ expression is directly mediated by these factors. It remains to be seen if a similar mechanism operates in Th17 cells. Therefore, while $\gamma \delta \mathrm{T} 17$ and Th17 cells both lose CCR6 expression during inflammation, the mechanism and function of this process may differ between these populations.

Investigating the trafficking of human $\gamma \delta \mathrm{T} 17$ cells is of clinical relevance as they are increasingly implicated in autoimmunity and cancer, and it will be important to determine whether the model we have established here for murine $\gamma \delta \mathrm{T} 17$ cells applies to humans. Of interest, CCR6 is known to be expressed by both $\mathrm{V} \delta 1^{+}$and $\mathrm{V} \delta 2^{+} \gamma \delta \mathrm{T} 17$ cells in humans, as well as by circulating $\mathrm{V} \delta 2^{+}$cells with a skin-homing CLA ${ }^{+}$phenotype ${ }^{1-53}$. CCR2 expression has been identified in human $\gamma \delta \mathrm{T}$ cells, but to our knowledge this has not been examined specifically in IL-17 ${ }^{+}$ cells $^{54,55}$. Whether human $\gamma \delta \mathrm{T} 17$ cells also undergo activationinduced CCR6 downregulation to enhance inflammatory homing has yet to be determined. While the human dermal $\gamma \delta \mathrm{T} 17$ cell compartment is relatively small compared to the murine system, the relative abundance of circulating skin-homing $\mathrm{V} \delta 2^{+}$cells suggests that similar recirculation mechanisms may also operate in humans ${ }^{8,52}$. These issues await further experimental resolution.

Our description of $\gamma \delta \mathrm{T} 17$ cell trafficking between homeostasis and inflammation presents a novel mode of lymphocyte migration. Conventional $\mathrm{T}$ cells downregulate the homeostatic recirculation signal CCR7 and induce expression of inflammatory chemokine receptors upon differentiation into effector subsets, a slow process. In contrast, we show that $\gamma \delta \mathrm{T} 17$ cells constitutively co-express homeostatic and inflammatory homing receptors. The switch in $\gamma \delta \mathrm{T} 17$ cell trafficking from homeostatic to inflammatory programs is solely driven by downregulation of the homeostatic receptor CCR6, rather than induction of additional inflammatory homing receptors. This model likely facilitates immediate homing to inflammatory sites in addition to homeostatic scanning behaviour, consistent with the 'activatedbut-resting' phenotype of $\gamma \delta \mathrm{T} 17$ cells. Use of CCR6 expression to distinguish resting and activated states may facilitate future investigation of $\gamma \delta \mathrm{T} 17$ cell biology. We conclude that $\gamma \delta \mathrm{T} 17$ cells exhibit a unique bi-phasic trafficking program driven by programmed changes in homing receptor expression to facilitate tissue sentinel responses and rapid homing to distal inflammatory sites.

\section{Methods}

Mice. C57Bl/6 (WT) and Ly5.1 mice were purchased from Animal Resource Centre (WA, Australia) or bred at the University of Adelaide animal facility.

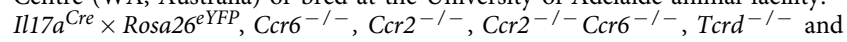


C57Bl $/ 6 \times$ Ly5.1 $\left(\mathrm{F}_{1}\right)$ mice were bred at the University of Adelaide animal facility.

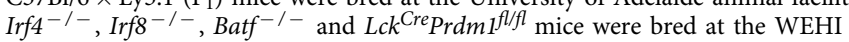
animal facility. Mice were age- and gender-matched and used at 6-14 weeks of age. Experiments were conducted with approval of the University of Adelaide Animal Ethics Committee.

Disease models. Mice were immunized for chronic EAE by subcutaneous injection of $100 \mu \mathrm{g}$ of $\mathrm{MOG}_{35-55}$ (GL Biochem) in phosphate-buffered saline (PBS) emulsified 1:1 in complete Freund's adjuvant, coupled with i.p. injection of $300 \mathrm{ng}$ Pertussis toxin (Sapphire Bioscience) on days 0 and 2. Mice were analysed at clinical scores of 0.5 (onset) and 2-3 (peak) in wild type (WT) mice, where scoring criteria were: 0.5 tremor, 1 partially limp tail, 2 fully limp tail, 2.25 unable to right, 2.5 sprawled hindlimbs, 2.75 one hindlimb paralysed, 3 both hindlimbs paralysed, 3.5 one forelimb paralysed. B16.F10 melanoma cells (provided by Prof. Mark Smyth, QIMR Berghofer, mycoplasma free and verified by short tandem repeat) were cultured in RPMI 1640 containing $10 \%$ fetal calf serum (FCS) and $5 \times 10^{4}$ cells were injected subcutaneously into mice at four sites. S. pneumoniae EF3030 was grown to a $\mathrm{D}_{600}$ of 0.18 in nutrient broth with $10 \%$ horse serum at $37^{\circ} \mathrm{C} 5 \% \mathrm{CO}_{2}$ and stored at $-80^{\circ} \mathrm{C}$. Stocks were defrosted and $1 \times 10^{6}$ colony-forming units were delivered intranasally. Bacterial load was determined by serial dilution of concentrated NW onto blood agar with $5 \mu \mathrm{g} \mathrm{ml}^{-1}$ gentamicin (Sigma).

Cell preparation. Single-cell suspensions were prepared from lymphoid organs by pressing through $70 \mu \mathrm{m}$ filters. Peripheral blood was collected into heparinized Vacutainer tubes (BD). Red blood cells were lysed as required. CNS from PBS-perfused mice was pressed through $70 \mu \mathrm{m}$ filters and then separated over a 30/70\% Percoll (GE) gradient at 500g. The following digestions were performed at $37^{\circ} \mathrm{C}$ with $30 \mathrm{U} \mathrm{ml}^{-1}$ DNase (Sigma). Epidermis and dermis from ears or shaved trunk skin were separated by incubation in $0.375 \%$ tryspin for $2 \mathrm{~h}$ at $37^{\circ} \mathrm{C}$, and then digested separately with $85 \mu^{g^{-1} l^{-1}}$ Liberase TM (Roche) for $1 \mathrm{~h}$. Tumours and perfused lungs were digested in $2 \mathrm{mg} \mathrm{ml}^{-1}$ collagenase (Sigma) for $1 \mathrm{~h}$. NP tissue between the nose tip and eyes was dissected following removal of nasal-associated lymphoid tissue, digested with $2 \mathrm{mg} \mathrm{ml}^{-1}$ collagenase for $1.5 \mathrm{~h}$ and separated by a $40 / 80 \%$ Percoll gradient at $600 \mathrm{~g}$. Livers were pressed through $70 \mu \mathrm{m}$ filters and then lymphocytes were isolated by a $37.5 \%$ Percoll gradient at $850 \mathrm{~g}$. Flushed and longitudinally opened small intestine free of Peyer's patches was washed in PBS then incubated in $5 \mathrm{mM}$ EDTA for $40 \mathrm{~min}$ at $37^{\circ} \mathrm{C}$ to remove epithelium, before remaining lamina propria was digested with $0.5 \mathrm{mg} \mathrm{ml}^{-1}$ collagenase for $1.5 \mathrm{~h}$ at $37^{\circ} \mathrm{C}$ and separated over a $40 / 80 \%$ Percoll gradient at $1,000 \mathrm{~g}$ to isolate lamina propria lymphocytes. Peritoneal exudate cells were collected by $3 \times 1 \mathrm{ml}$ PBS washes.

Flow cytometry. Single-cell suspensions were stained in 96-well round- or v-bottom plates (Corning) at $2 \times 10^{6}$ lymphocytes per well using antibodies and other reagents detailed in Supplementary Table 1. For intracellular cytokine staining, cells were first incubated in complete IMDM with $20 \mathrm{pg} \mathrm{ml}^{-1}$ PMA (Life Technologies), $1 \mathrm{nM}$ ionomycin (Life Technologies) and 1/1,500 GolgiStop (BD) for $4 \mathrm{~h}$ at $37^{\circ} \mathrm{C}$. Cells were washed in PBS and stained with Near Infrared fixable dye diluted 1/1,000 (Life Technologies) for $15 \mathrm{~min}$ at room temperature. Cells were then washed with FACS buffer (PBS $1 \%$ bovine serum albumin $0.04 \%$ azide) and blocked with mouse $\gamma$-globulin $(\mathrm{m} \gamma \mathrm{g})\left(200 \mu \mathrm{g} \mathrm{ml}^{-1}\right)$ for $5 \mathrm{~min}$ at room temperature. All subsequent steps were incubated at $4{ }^{\circ} \mathrm{C}$. For purified antibodies, cells were stained with purified antibody for 20-60 min, washed in FACS buffer, stained with secondary antibody in $\mathrm{m} \gamma \mathrm{g}\left(200 \mu \mathrm{g} \mathrm{ml}{ }^{-1}\right)$ and normal mouse serum (NMS) (1\%) for 20 min, washed in FACS buffer and blocked with rat $\gamma$-globulin for $15 \mathrm{~min}$. Cells were stained with directly conjugated and biotinylated antibodies for $20 \mathrm{~min}$. In the case of biotinylated antibodies, cells were then washed in FACS buffer and stained with streptavidin for $15 \mathrm{~min}$. Cells were then washed in PBS $0.04 \%$ azide. For intracellular cytokine staining, cells were incubated in Cytofix/Cytoperm (BD) for 20 min, washed in Permwash (BD) and stained with intracellular directly conjugated antibodies for $20 \mathrm{~min}$. For transcription factor staining, cells were incubated in Foxp3 kit perm buffer (eBioscience) for 30 min to overnight, and then washed in Foxp3 kit permwash (eBioscience). Cells were then stained with directly conjugated $\alpha$-transcription factor antibodies in NMS (2\%) and normal rat serum (2\%), and then washed in PBS $0.04 \%$ azide. All stains were washed in PBS 0.04\% azide, resuspended in PBS 1\% paraformaldehyde and stored at $4{ }^{\circ} \mathrm{C}$ in the dark.

Specificity of $\alpha$-CCR2 was confirmed by negative staining on $\mathrm{Ccr}^{-/-} \gamma \delta \mathrm{T} 17$ cells. CCR2 and CCR6 gating was determined by relevant isotype controls. For measurement of fluorescence intensity, relevant isotype control geometric mean fluorescence intensity was subtracted from raw geometric mean fluorescence intensity value. For in vivo proliferation analysis, mice were given $2 \mathrm{mg} \mathrm{BrdU}$ i.p. and then drinking water with $0.8 \mathrm{mg} \mathrm{ml}^{-1} \mathrm{BrdU} 2 \%$ glucose. Following restimulation and surface staining, cells were permeabilized, DNase-treated and stained with $\alpha$-BrdU (BD) according to the manufacturer's instructions. For in vitro proliferation analysis, cells were labelled with Cell Proliferation Dye (eBioscience) according to the manufacturer's instructions. Flow cytometry was acquired on a BD LSR II or FACSAria and analysed with FlowJo (Treestar). Gating strategies are detailed in Supplementary Fig. 8.

$\gamma \delta \mathrm{T} 17$ cell expansion culture and retroviral transduction. Pooled spleen and $\mathrm{LN}$ cells were cultured at $1 \times 10^{6}$ cells per ml in RPMI 1640 containing $10 \%$ FCS, antibiotics, $1 \times$ Glutamax (Gibco), $10 \mathrm{mM}$ HEPES (SA Pathology), $1 \mathrm{mM}$ sodium pyruvate, $54 \mathrm{pM} \beta$-mercaptoethanol and $1 \times$ non-essential amino acids (Gibco) with $5 \mathrm{ng} \mathrm{ml}^{-1}$ recombinant (r)IL-23 (eBioscience), $5 \mathrm{ng} \mathrm{ml}^{-1} \mathrm{rIL}-1 \beta$ (Miltenyi Biotec) and $10 \mu \mathrm{g} \mathrm{ml}^{-1} \alpha$-IFN- $\gamma$ (BioXCell) in 96-well round-bottom plates coated with $1 \mu \mathrm{g} \mathrm{ml}^{-1} \alpha$-TCR- $\gamma \delta$ (clone GL3; Biolegend) for 3 days. Cells were washed and re-seeded on fresh plastic at $1 \times 10^{6}$ cells per $\mathrm{ml}$ for a further 3 days as above without TCR- $\gamma \delta$ stimulation. Cells were then washed and re-seeded in $20 \mathrm{ng} \mathrm{ml}^{-1}$ rIL-7 (Peprotech) and $10 \mu \mathrm{g} \mathrm{ml}^{-1} \alpha$-IFN- $\gamma$ for a further 3 days. pMIG, pMIG-Rorc and pMIG-Ccr6 (cloned from mouse Ccr6 cDNA) were transfected into EcoPack 2 293 cells (Clontech; mycoplasma free) with Lipofectamine 2000 (ThermoFisher), and supernatant collected after $48 \mathrm{~h}$. $\gamma \delta \mathrm{T} 17$ cells at days 4 and 5 of culture were centrifuged at 2,500 r.p.m. $\left(30^{\circ} \mathrm{C}\right.$ for $\left.1.5 \mathrm{~h}\right)$ in supernatant with $8 \mu \mathrm{g} \mathrm{ml}^{-1}$ polybrene (Sigma) in flat-bottom 96 well trays before being returned to culture.

Adoptive transfers. For $\mathrm{Ccr}^{-/-}$and $\mathrm{Ccr}{ }^{\mathrm{tg}}$ trafficking experiments, $1-2 \times 10^{6}$ each of in vitro-expanded $\mathrm{F}_{1}\left(\mathrm{CD} 45.1^{+} \mathrm{CD} 45.2^{+}\right)$and $\mathrm{Ccr} 2^{-/-}\left(\mathrm{CD} 45.2^{+}\right)$, or transduced control and $\mathrm{Ccr}^{\mathrm{tg}} \gamma \delta \mathrm{T} 17$ cells $\left(\mathrm{F}_{1}\right.$ or WT), were mixed and transferred i.v. into Ly5.1 $\left(\mathrm{CD} 45.1^{+}\right)$recipient mice d5 post-challenge with B16 melanoma, d8-10 post EAE induction or $24 \mathrm{~h}$ post-S. pneumoniae infection. $\gamma \delta \mathrm{T} 17$ cell infiltration of target organs was analysed $24-48$ h post-transfer, and CD 45 congenic ratios were normalized to input sample. For S. pneumoniae $\mathrm{Tcrd}^{-1-}$ reconstitution, in vitro-expanded WT and $C c r 2^{-/-} \gamma \delta \mathrm{T} 17$ cells were further purified by MACS (Miltenyi Biotec) before $3 \times 10^{6}$ cells were transferred into separate Tcrd $^{-/-}$hosts $24 \mathrm{~h}$ prior to infection. For naïve dermis trafficking experiments, $5-10 \times 10^{7}$ fresh WT or $\mathrm{Ccr}^{-/-}$lymphocytes or $3 \times 10^{7} 72 \mathrm{~h} \mathrm{IL-23/IL-1 \beta -}$ stimulated WT lymphocytes were transferred into separate unimmunized Ly5.1 mice and analysed $36 \mathrm{~h}$ later. Number of recovered cells was normalized to number of $\gamma \delta \mathrm{T} 17$ cells transferred.

ELISA. Tumour and NP supernatants from digested samples and supernatants from filtered CNS were supplemented with protease inhibitors (Sigma) and stored at $-80^{\circ} \mathrm{C}$. Mouse CCL2 Duoset ELISA (R\&D) was conducted according to the manufacturer's instructions.

qPCR. $\gamma \delta$ T cells from $I l 17 a^{C r e} \times$ Rose $26^{e Y F P}$ mice were enriched by MACS using mouse TCR $\gamma \delta^{+}$isolation kit (Miltenyi Biotec, \# 130-092-125), and then sorted using a BD FACSAria. Naïve CD $4^{+} \mathrm{T}$ cells were sorted from WT splenocytes, and skin stromal populations were sorted from digested epidermal and dermal suspensions from WT mice. Sorting strategies are detailed in Supplementary Figure 9. RNA was extracted from sorted cells using Qiagen RNeasy Micro kit (\# 74004). For epidermis and dermis, tissues were snap frozen in liquid nitrogen, crushed with mortar and pestle and RNA purified using Qiagen RNeasy Mini kit (\# 74104) according to the manufacturer's instructions. cDNA was generated with the Roche Transcriptor First Strand cDNA synthesis kit (\# 04896866001). qPCR was performed with Roche LightCycler 480 SYBR Green I master mix (\# 04887352001) using primer sequences in Supplementary Table 2 on a LightCycler 480 instrument (Roche). Relative gene expression was calculated as $2^{- \text {(CI target-CT reference) }}$ where reference was Rplpo.

Chemotaxis. Splenocytes were rested in complete RPMI for $3-4 \mathrm{~h}$ at $37^{\circ} \mathrm{C}$, washed and suspended in chemotaxis buffer (RPMI $0.5 \%$ bovine serum albumin $20 \mathrm{mM}$ HEPES). $\gamma \delta \mathrm{T} 17$ cells from culture were washed and suspended in chemotaxis buffer. CCL2 or CCL20 (from the late Prof. Ian Clark-Lewis) were diluted in chemotaxis buffer and loaded into the lower chambers of 96 -well $5 \mu \mathrm{m}$ pore transwell plates (Corning). $2 \times 10^{6}$ splenocytes or $2 \times 10^{5}$ in vitro-expanded $\gamma \delta \mathrm{T} 17$ cells were loaded into the upper chambers and plates were incubated at $37^{\circ} \mathrm{C}$ for $3 \mathrm{~h}$. Lower wells were harvested and stained for flow cytometry. CountBrite beads (Invitrogen) were added to samples prior to acquisition to normalize event counts. Chemotaxis index was calculated as number of gated events divided by number in 0 chemokine control.

In vitro stimulation. Splenocytes were cultured in complete IMDM (10\% FCS, pen/strep, L-glutamine, $\beta$-mercaptoethanol) at $2.5 \times 10^{6}$ cells per $\mathrm{ml}$ with $10 \mathrm{ng} \mathrm{ml}^{-1} \mathrm{rIL}^{-23}$ (eBioscience), $10 \mathrm{ng} \mathrm{ml}^{-1} \mathrm{rIL}-1 \beta$ (Miltenyi Biotec), $20 \mathrm{ng} \mathrm{ml}^{-1}$ rIL-7 (Peprotech), $10 \mathrm{ng} \mathrm{ml}^{-1}$ rIL-12 (R\&D), $10 \mathrm{ng} \mathrm{ml}^{-1} \mathrm{rIL}-18$ (R\&D) and/or with pre-coating in $1 \mu \mathrm{g} \mathrm{ml}^{-1} \alpha$-TCR- $\gamma \delta$ (Biolegend) for up to $72 \mathrm{~h}$ at $37^{\circ} \mathrm{C}$. For mitomycin $C$ pre-treatment, cells were first incubated with $10 \mu \mathrm{g} \mathrm{ml}^{-1}$ mitomycin $\mathrm{C}$ (Sigma) in complete IMDM at $2 \times 10^{7}$ cells per $\mathrm{ml}$ for $2 \mathrm{~h}$ at $37^{\circ} \mathrm{C}$ before extensive washing.

ChIP-seq analysis. ChIP-seq data for IRF4 in CD8 ${ }^{+} \mathrm{T}_{\text {cells }}{ }^{45}$, BATF in CD8 ${ }^{+}$ $\mathrm{T}$ cells ${ }^{44}$ and IRF4/BATF in Th17 cells ${ }^{43}$ were previously published and were 
obtained from NCBI database using accession codes GSE49930, GSE54191 and GSE40918, respectively. BAM files were loaded and displayed using the IGB genome browser.

Statistics. Data were analysed with GraphPad Prism 6. Appropriate statistical tests were two-sided and used as indicated in figure legends. ${ }^{*} P<0.05,{ }^{*} P<0.01$, ${ }^{* * *} P<0.001,{ }^{* * * *} P<0.0001$. All replicates are biological except in $\mathrm{qPCR}$ experiments, where technical replicates are denoted. Sample sizes were determined empirically to ensure adequate power. Tcrd ${ }^{-1-}$ host mice were randomly assigned to groups before receiving adoptive transfers in Fig. 3f. No blinding was utilized. Minimal variance was generally observed between groups; Welch's correction was used in $t$-tests where standard deviations were significantly different. Most data sets were normally distributed; Mann-Whitney and Kruskal-Wallis tests were utilized where data were not normally distributed.

Data availability. Relevant data are available from authors upon reasonable request.

\section{References}

1. Sutton, C. E. et al. Interleukin-1 and IL-23 induce innate IL-17 production from gammadelta $\mathrm{T}$ cells, amplifying Th17 responses and autoimmunity. Immunity 31, 331-341 (2009).

2. Jensen, K. D. et al. Thymic selection determines gammadelta $\mathrm{T}$ cell effector fate: antigen-naive cells make interleukin-17 and antigen-experienced cells make interferon gamma. Immunity 29, 90-100 (2008).

3. Kashem, S. W. et al. Nociceptive sensory fibers drive interleukin-23 production from CD301b + dermal dendritic cells and drive protective cutaneous immunity. Immunity 43, 515-526 (2015).

4. Cao, J. et al. Activation of IL-27 signalling promotes development of postinfluenza pneumococcal pneumonia. EMBO Mol. Med. 6, 120-140 (2014).

5. Cho, J. S. et al. IL-17 is essential for host defense against cutaneous Staphylococcus aureus infection in mice. J. Clin. Invest. 120, 1762-1773 (2010).

6. Coffelt, S. B. et al. IL-17-producing gammadelta T cells and neutrophils conspire to promote breast cancer metastasis. Nature 522, 345-348 (2015).

7. Rei, M. et al. Murine CD27(-) Vgamma6(+) gammadelta T cells producing IL-17A promote ovarian cancer growth via mobilization of protumor small peritoneal macrophages. Proc. Natl Acad. Sci. USA 111, E3562-E3570 (2014).

8. Cai, Y. et al. Pivotal role of dermal IL-17-producing gammadelta T cells in skin inflammation. Immunity 35, 596-610 (2011).

9. Roark, C. L. et al. Exacerbation of collagen-induced arthritis by oligoclonal, IL-17-producing gamma delta T cells. J. Immunol. 179, 5576-5583 (2007).

10. Cai, Y. et al. Differential developmental requirement and peripheral regulation for dermal Vgamma4 and Vgamma6T17 cells in health and inflammation. Nat. Commun. 5, 3986 (2014).

11. Zhang, Y. et al. Migratory and adhesive cues controlling innate-like lymphocyte surveillance of the pathogen-exposed surface of the lymph node. Elife 5, E18156 (2016).

12. Nakamizo, S. et al. Dermal Vgamma4 (+ ) gammadelta $\mathrm{T}$ cells possess a migratory potency to the draining lymph nodes and modulate $\mathrm{CD} 8(+)$ T-cell activity through TNF-alpha production. J. Invest. Dermatol. 135, 1007-1015 (2015).

13. Maeda, Y. et al. IL-17-producing Vgamma4 + gammadelta T cells require sphingosine 1-phosphate receptor 1 for Their Egress from the lymph nodes under homeostatic and inflammatory conditions. J. Immunol. 195, 1408-1416 (2015).

14. Gray, E. E. et al. Deficiency in IL-17-committed Vgamma4(+) gammadelta $\mathrm{T}$ cells in a spontaneous Sox13-mutant CD45.1 $(+)$ congenic mouse substrain provides protection from dermatitis. Nat. Immunol. 14, 584-592 (2013).

15. Ramirez-Valle, F., Gray, E. E. \& Cyster, J. G. Inflammation induces dermal Vgamma4 + gammadeltaT17 memory-like cells that travel to distant skin and accelerate secondary IL-17-driven responses. Proc. Natl Acad. Sci. USA 112, 8046-8051 (2015).

16. Haas, J. D. et al. CCR6 and NK1.1 distinguish between IL-17A and IFN-gamma-producing gammadelta effector T cells. Eur. J. Immunol. 39, 3488-3497 (2009).

17. Hirota, K. et al. Preferential recruitment of CCR6-expressing Th17 cells to inflamed joints via CCL20 in rheumatoid arthritis and its animal model. J. Exp. Med. 204, 2803-2812 (2007).

18. Kara, E. E. et al. CCR2 defines in vivo development and homing of IL-23-driven GM-CSF-producing Th17 cells. Nat. Commun. 6, 8644 (2015).

19. Mabuchi, T. et al. CCR6 is required for epidermal trafficking of gammadelta-T cells in an IL-23-induced model of psoriasiform dermatitis. J. Invest. Dermatol. 133, 164-171 (2013).

20. Akitsu, A. et al. IL-1 receptor antagonist-deficient mice develop autoimmune arthritis due to intrinsic activation of IL-17-producing CCR2(+)Vgamma6( + )gammadelta T cells. Nat. Commun. 6, 7464 (2015).

21. Sumaria, N. et al. Cutaneous immunosurveillance by self-renewing dermal gammadelta T cells. J. Exp. Med. 208, 505-518 (2011).
22. Gray, E. E., Suzuki, K. \& Cyster, J. G. Cutting edge: identification of a motile IL-17-producing gammadelta T cell population in the dermis. J. Immunol. 186, 6091-6095 (2011).

23. Hirota, K. et al. Fate mapping of IL-17-producing T cells in inflammatory responses. Nat. Immunol. 12, 255-263 (2011).

24. Ribot, J. C. et al. CD27 is a thymic determinant of the balance between interferon-gamma- and interleukin 17-producing gammadelta $\mathrm{T}$ cell subsets. Nat. Immunol. 10, 427-436 (2009).

25. Paget, C. et al. CD3bright signals on gammadelta $\mathrm{T}$ cells identify IL-17A-producing Vgamma6Vdelta1 + T cells. Immunol. Cell Biol. 93, 198-212 (2015).

26. Lalor, S. J. et al. Caspase-1-processed cytokines IL-1beta and IL-18 promote IL-17 production by gammadelta and CD4 $\mathrm{T}$ cells that mediate autoimmunity. J. Immunol. 186, 5738-5748 (2011).

27. Michel, M. L. et al. Interleukin 7 (IL-7) selectively promotes mouse and human IL-17-producing gammadelta cells. Proc. Natl Acad. Sci. USA 109, 17549-17554 (2012).

28. Blink, S. E. et al. gammadelta $\mathrm{T}$ cell subsets play opposing roles in regulating experimental autoimmune encephalomyelitis. Cell Immunol. 290, 39-51 (2014).

29. Kulig, P. et al. IL-12 protects from psoriasiform skin inflammation. Nat. Commun. 7, 13466 (2016).

30. Li, J., Liu, J., Mao, X., Tang, Q. \& Lu, H. IL-7 receptor blockade inhibits IL-17-producing gammadelta cells and suppresses melanoma development. Inflammation 37, 1444-1452 (2014).

31. Tang, Q. et al. Hmgb1-IL-23-IL-17-IL-6-Stat3 axis promotes tumor growth in murine models of melanoma. Mediators Inflamm. 2013, 713859 (2013).

32. Petermann, F. et al. gammadelta $\mathrm{T}$ cells enhance autoimmunity by restraining regulatory $\mathrm{T}$ cell responses via an interleukin-23-dependent mechanism. Immunity 33, 351-363 (2010).

33. Fife, B. T., Huffnagle, G. B., Kuziel, W. A. \& Karpus, W. J. CC chemokine receptor 2 is critical for induction of experimental autoimmune encephalomyelitis. J. Exp. Med. 192, 899-905 (2000).

34. Nagao, K. et al. Stress-induced production of chemokines by hair follicles regulates the trafficking of dendritic cells in skin. Nat. Immunol. 13, 744-752 (2012).

35. Zhao, X. et al. CCL9 is secreted by the follicle-associated epithelium and recruits dome region Peyer's patch CD11b + dendritic cells. J. Immunol. 171, 2797-2803 (2003).

36. Varona, R. et al. Molecular cloning, functional characterization and mRNA expression analysis of the murine chemokine receptor CCR6 and its specific ligand MIP-3alpha. FEBS Lett. 440, 188-194 (1998).

37. Comerford, I. et al. An immune paradox: how can the same chemokine axis regulate both immune tolerance and activation?: CCR6/CCL20: a chemokine axis balancing immunological tolerance and inflammation in autoimmune disease. Bioessays 32, 1067-1076 (2010).

38. Charbonnier, A. S. et al. Macrophage inflammatory protein 3alpha is involved in the constitutive trafficking of epidermal langerhans cells. J. Exp. Med. 190, 1755-1768 (1999).

39. Cretney, E. et al. The transcription factors Blimp-1 and IRF4 jointly control the differentiation and function of effector regulatory T cells. Nat. Immunol. 12, 304-311 (2011).

40. Newman, D. M., Leung, P. S., Putoczki, T. L., Nutt, S. L. \& Cretney, E. Th17 cell differentiation proceeds independently of IRF8. Immunol. Cell Biol. 94, 796-801 (2016).

41. Ouyang, X. et al. Transcription factor IRF8 directs a silencing programme for TH17 cell differentiation. Nat. Commun. 2, 314 (2011).

42. Jain, R. et al. Interleukin-23-induced transcription factor Blimp-1 promotes pathogenicity of T helper 17 cells. Immunity 44, 131-142 (2016).

43. Ciofani, M. et al. A validated regulatory network for Th17 cell specification. Cell 151, 289-303 (2012)

44. Kurachi, M. et al. The transcription factor BATF operates as an essential differentiation checkpoint in early effector CD8 + T cells. Nat. Immunol. 15, 373-383 (2014).

45. Man, K. et al. The transcription factor IRF4 is essential for TCR affinitymediated metabolic programming and clonal expansion of T cells. Nat. Immunol. 14, 1155-1165 (2013).

46. Gerner, M. Y., Torabi-Parizi, P. \& Germain, R. N. Strategically localized dendritic cells promote rapid $\mathrm{T}$ cell responses to lymph-borne particulate antigens. Immunity 42, 172-185 (2015).

47. Hammerich, L. et al. Chemokine receptor CCR6-dependent accumulation of gammadelta $\mathrm{T}$ cells in injured liver restricts hepatic inflammation and fibrosis Hepatology 59, 630-642 (2014).

48. Riol-Blanco, L. et al. Nociceptive sensory neurons drive interleukin-23mediated psoriasiform skin inflammation. Nature 510, 157-161 (2014).

49. Barros-Martins, J. et al. Effector gammadelta T cell differentiation relies on Master but not auxiliary Th cell transcription factors. J. Immunol. 196, 3642-3652 (2016). 
50. Raifer, H. et al. Unlike alphabeta T cells, gammadelta T cells, LTi cells and NKT cells do not require IRF4 for the production of IL-17A and IL-22. Eur. J. Immunol. 42, 3189-3201 (2012).

51. Wu, P. et al. gammadeltaT17 cells promote the accumulation and expansion of myeloid-derived suppressor cells in human colorectal cancer. Immunity 40, 785-800 (2014)

52. Laggner, U. et al. Identification of a novel proinflammatory human skin-homing Vgamma9Vdelta2 $\mathrm{T}$ cell subset with a potential role in psoriasis. J. Immunol. 187, 2783-2793 (2011).

53. Caccamo, N. et al. Differentiation, phenotype, and function of interleukin-17producing human Vgamma9Vdelta2 T cells. Blood 118, 129-138 (2011).

54. Lanca, T. et al. Protective role of the inflammatory CCR2/CCL2 chemokine pathway through recruitment of type 1 cytotoxic gammadelta $\mathrm{T}$ lymphocytes to tumor beds. J. Immunol. 190, 6673-6680 (2013).

55. Brandes, M. et al. Flexible migration program regulates gamma delta T-cell involvement in humoral immunity. Blood 102, 3693-3701 (2003).

\section{Acknowledgements}

We thank Prof. Ian Frazer (UQ Diamantina Institute, Australia), Prof. Brigitta Stockinger (Francis Crick Institute, UK) and Prof. Christian Engwerda (QIMR Berghofer, Australia) for mice and Prof. Dan Littman (New York University, USA) for pMIG-Rorc (Addgene \#24069). We also thank the late Prof. Ian Clark-Lewis for chemokine ligands and staff at Laboratory Animal Services from University of Adelaide for animal husbandry. This work was supported by National Health and Medical Research Council project grants 1066781 and 1054925. A.K. is supported by the Sylvia and Charles Viertel foundation.

\section{Author contributions}

D.R.M., E.E.K., I.C. and S.R.M. designed experiments, analysed data and wrote the manuscript; D.R.M. performed most experiments; E.E.K., C.R.B., T.S.T., K.A.F., C.E.G and J.J.W. performed experiments; R.B. and J.C.P. contributed to S. pneumoniae experiments; A.K. and S.L.N. contributed to transcription factor experiments; A.B. contributed to retrovirus experiments; M.M. provided key reagents; J.C.P., A.K., S.L.N., A.B. and M.M. edited the manuscript; I.C. and S.R.M. supervised the study and attained funding.

\section{Additional information}

Supplementary Information accompanies this paper at http://www.nature.com/ naturecommunications

Competing interests: The authors declare no competing financial interests.

Reprints and permission information is available online at http://npg.nature.com/ reprintsandpermissions/

How to cite this article: McKenzie, D. R. et al. IL-17-producing $\gamma \delta$ T cells switch migratory patterns between resting and activated states. Nat. Commun. 8, 15632 doi: $10.1038 /$ ncomms15632 (2017)

Publisher's note: Springer Nature remains neutral with regard to jurisdictional claims in published maps and institutional affiliations.

\section{(c) (1)}

This work is licensed under a Creative Commons Attribution 4.0 International License. The images or other third party material in this article are included in the article's Creative Commons license, unless indicated otherwise in the credit line; if the material is not included under the Creative Commons license, users will need to obtain permission from the license holder to reproduce the material. To view a copy of this license, visit http://creativecommons.org/licenses/by/4.0/

(C) The Author(s) 2017 